\title{
Beluga whale (Delphinapterus leucas) vocalizations and call classification from the eastern Beaufort Sea population
}

\author{
Ellen C. Garland, ${ }^{\text {a) }}$ Manuel Castellote, ${ }^{\text {b) }}$ and Catherine L. Berchok \\ National Marine Mammal Laboratory, Alaska Fisheries Science Center, National Marine Fisheries Service, \\ National Oceanic and Atmospheric Administration, 7600 Sand Point Way NE, Seattle, Washington 98115. \\ USA
}

(Received 2 December 2014; revised 1 April 2015; accepted 12 April 2015)

\begin{abstract}
Beluga whales, Delphinapterus leucas, have a graded call system; call types exist on a continuum making classification challenging. A description of vocalizations from the eastern Beaufort Sea beluga population during its spring migration are presented here, using both a non-parametric classification tree analysis (CART), and a Random Forest analysis. Twelve frequency and duration measurements were made on 1019 calls recorded over 14 days off Icy Cape, Alaska, resulting in 34 identifiable call types with $83 \%$ agreement in classification for both CART and Random Forest analyses. This high level of agreement in classification, with an initial subjective classification of calls into 36 categories, demonstrates that the methods applied here provide a quantitative analysis of a graded call dataset. Further, as calls cannot be attributed to individuals using single sensor passive acoustic monitoring efforts, these methods provide a comprehensive analysis of data where the influence of pseudo-replication of calls from individuals is unknown. This study is the first to describe the vocal repertoire of a beluga population using a robust and repeatable methodology. A baseline eastern Beaufort Sea beluga population repertoire is presented here, against which the call repertoire of other seasonally sympatric Alaskan beluga populations can be compared.
\end{abstract}

[http://dx.doi.org/10.1121/1.4919338]

[WWA]

Pages: $3054-3067$

\section{INTRODUCTION}

Variation in vocal displays can be used as a powerful tool for inferring group separation, allowing for the recognition of distinct populations. Dialect differences have been used to indicate structure in many bird species such as mountain white-crowned sparrows (Zonotrichia leucophrys oriantha; MacDougall-Shackleton and MacDougallShackleton, 2001) and yellow-naped amazon parrots (Amazona auropalliata and A. ochrocephala; Wright and Wilkinson, 2001) as well as a diverse array of other taxa including rock hyraxes (Procavia capensis; Kershenbaum et al., 2012), sperm whales (Physeter macrocephalus; Whitehead et al., 1998), fin whales (Balaenoptera physalus; Delarue et al., 2009), killer whales (Orcinus orca; Ford, 1991), and humpback whales (Megaptera novaeangliae; Garland et al., 2013). For example, killer whales display subtle differences in the structure of calls among different matrilines within a pod (Miller and Bain, 2000), while differences in the use and structure of calls exist among pods to produce a group-specific dialect (Ford, 1991). Understanding the acoustic behavior of highly vocal species can assist in defining groupings through differences in population-specific vocal repertoires, which have the potential to allow sympatric populations to be differentiated and aid in the assessment of human impacts (such as noise or oil spills) to a discrete population level. Here we present the first description of the vocal repertoire of the eastern Beaufort

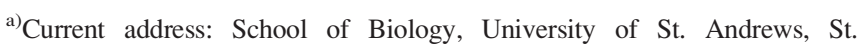
Andrews, Fife, KY16 9TH, UK. Electronic mail: ellen.garland@gmail.com b) Also at North Gulf Oceanic Society, 3430 Main Street, Homer, AK 99603, USA.
}

Sea beluga (Delphinapterus leucas) population during its spring migration, which provides a baseline against which the call repertoire of other seasonally sympatric Alaskan beluga populations can be compared to investigate population structure.

Belugas are highly vocal; these "canaries of the sea" produce a wide variety of calls like other delphinids that can be classified as whistles, pulsed calls, noisy calls, combined calls, and echolocation clicks (Au et al., 1985; Sjare and Smith, 1986; Faucher, 1988; Bel'kovich and Shchekotov, 1990; Angiel, 1997; Karlsen et al., 2002; Belikov and Bel'kovich, 2007, 2008; Chmelnitsky and Ferguson, 2012; Panova et al., 2012). These calls range in frequency from approximately $200 \mathrm{~Hz}$ to $20 \mathrm{kHz}$ with echolocation clicks extending upward of $120 \mathrm{kHz}$ (Au et al., 1985; Sjare and Smith, 1986). Whistles are narrowband tonal calls that are typically categorized into different call types based on their fundamental frequency and contour (Sjare and Smith, 1986). Pulsed calls display a larger frequency range (i.e., broadband) and are composed of a series of pulses. Differences in the pulse repetition rate (PRR) are used to assign call types (measured using the harmonic interval; Watkins, 1967). If no discernible pulses are evident (i.e., the PRR cannot be measured), the call is classified as a noisy call (Sjare and Smith, 1986). Combined calls, as the name suggests, consistently combine two calls (e.g., a pulse and whistle) simultaneously or as a sequence, to represent a distinct call type (Faucher, 1988). Finally, echolocation clicks (including restricted frequency click series) are broadband pulses that range in frequency from $200 \mathrm{~Hz}$ to $120 \mathrm{kHz}$ and primarily function in navigation and prey capture (Au et al., 1985; Sjare and Smith, 1986). 
Beluga vocalizations have been studied in a number of locations worldwide, including the following: the White Sea, Russia (Bel'kovich and Shchekotov, 1990); Svalbard, Norway (Karlsen et al., 2002); Cunningham Inlet, Northwest Territories, Canadian Arctic (Sjare and Smith, 1986); the St. Lawrence River Estuary, Canada (Faucher, 1988); Churchill River, Hudson Bay, Canada (Chmelnitsky and Ferguson, 2012); and Bristol Bay, Alaska (Angiel, 1997). These studies indicate there are a number of similarities in the call types examined, but also the presence of novel call types per location, suggesting that geographic differences exist among distant populations (Karlsen et al., 2002).

Beluga calls are graded; call types exist on a continuum making classification challenging (Karlsen et al., 2002). Calls are typically classified subjectively (qualitatively) using different classification schemes (e.g., Sjare and Smith, 1986; Bel'kovich and Shchekotov, 1990). Some authors have statistically investigated a subset of calls using cluster analyses to assign categories, validate their classification, or both (Angiel, 1997; Karlsen et al., 2002; Chmelnitsky and Ferguson, 2012). These analyses have had varying levels of success due to the graded nature of the signals, the resulting inclusion of multiple qualitative call types within a cluster, and the issue of auto-correlated variables being included in the analysis (Karlsen et al., 2002; Chmelnitsky and Ferguson, 2012). In addition, a lack of consistency in classification schemes and analysis methods among studies continues to hinder any quantitative comparison between repertoire descriptions across beluga populations. Currently, this can only be accomplished by comparing spectrograms of varying quality in publications; a robust statistical method to define and compare these difficult to categorize graded call types is required.

Within the Alaska region (Fig. 1), there are five genetically distinct beluga populations (O'Corry-Crowe et al.,
1997). These include three migratory and seasonally sympatric populations, the eastern Beaufort Sea, the eastern Chukchi Sea, and the eastern Bering Sea, which have distinct summer concentration areas and a shared wintering ground (see Allen and Angliss, 2013). The two remaining populations of Bristol Bay and Cook Inlet are resident and non-migratory and do not overlap in distribution (see Allen and Angliss, 2013). The large eastern Beaufort Sea population (minimum population size 39258 ) overwinters in the Bering Sea before migrating through the eastern Chukchi Sea in spring, to summer in the Mackenzie Delta, Amundsen Gulf, and surrounding areas in the Canadian Beaufort region (see Allen and Angliss, 2013). There is seasonal overlap (in latesummer and early- to mid-autumn) in the Beaufort and Chukchi Seas, between the eastern Chukchi Sea and eastern Beaufort Sea beluga populations (Hauser et al., 2014), and in winter in the Bering Sea among all migratory populations (Seaman et al., 1985). Differences in population-specific vocal repertoires have the potential to allow the sympatric populations to be differentiated (similar to other delphinid species). This study is the first to describe the calls of the seasonally sympatric eastern Beaufort Sea beluga population during their spring migration, using a non-parametric classification tree analysis (CART) and a Random Forest analysis, both novel quantitative methods for belugas, to provide a baseline for investigating population structure in a region containing a number of sympatric populations.

\section{METHODS}

\section{A. Acoustic recording}

Beluga calls included in this study were recorded on a long-term sub-surface passive acoustic mooring located 40 miles northwest of Icy Cape, Alaska (70.798 N, 163.081 W, depth $=43 \mathrm{~m}$ ), in the northeastern Chukchi Sea (Fig. 1). The

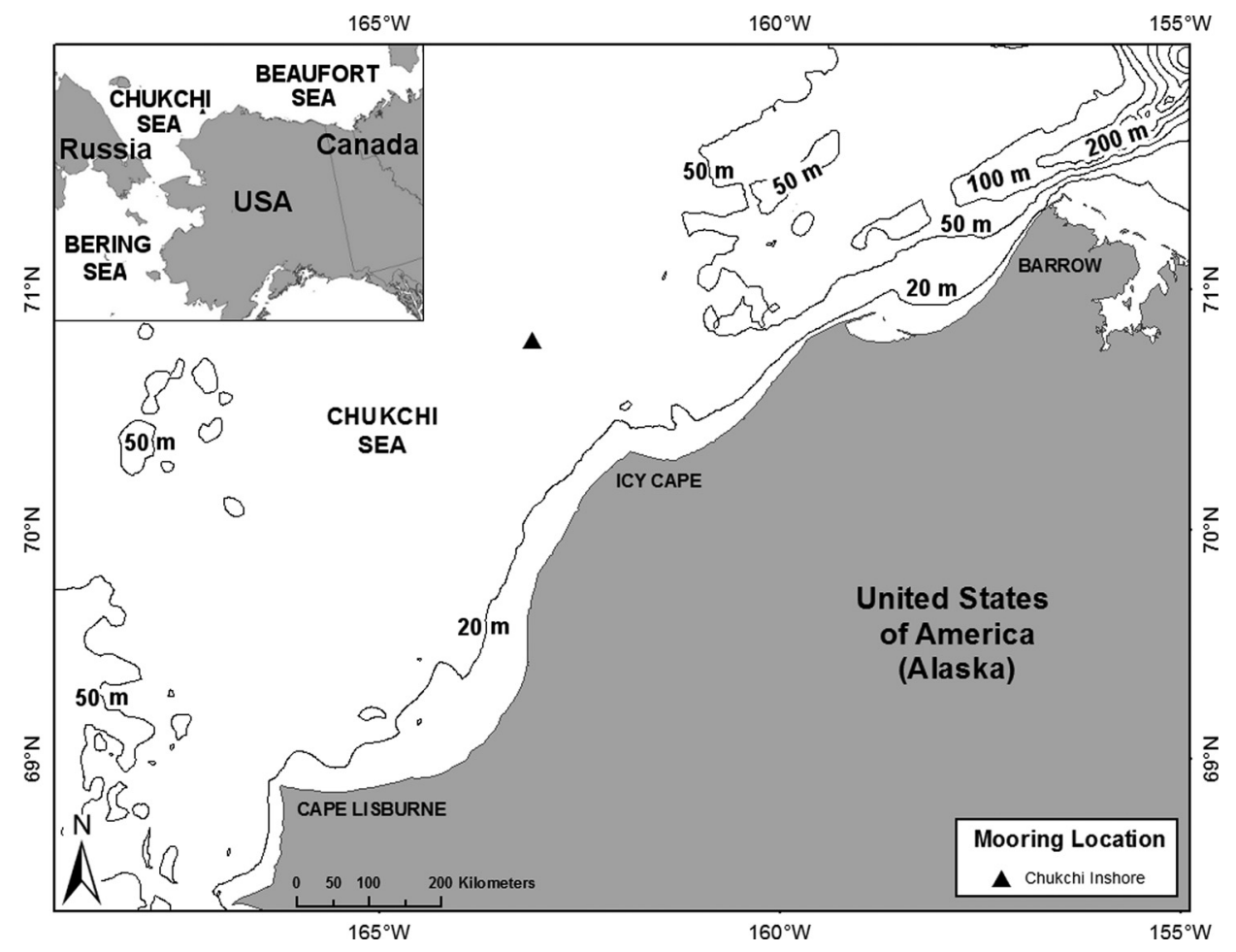

FIG. 1. Map of the Alaska Arctic region and recorder location. Mooring icon size exceeds approximate call detection range for belugas. 
mooring (deployed from 28 August 2010 to 25 August 2011) had an Autonomous Underwater Recorder for Acoustic Listening (AURAL; Multi-Électronique, Canada) ${ }^{1}$ with an HTI-96-min hydrophone (flat frequency response from $2 \mathrm{~Hz}$ to $30 \mathrm{kHz}$ and sensitivity of $-164 \mathrm{~dB}$ re $1 \mathrm{~V} / \mu \mathrm{Pa}$ ). The AURAL sampled at $16 \mathrm{kHz}$ with a $+16 \mathrm{~dB}$ gain, 16 bit resolution, and effective bandwidth of $\sim 10 \mathrm{~Hz}$ to $8 \mathrm{kHz}$ on a recording duty cycle of $95 \mathrm{~min}$ every $300 \mathrm{~min}$ (32\%). The mooring recorded from 10 September 2010 to 27 June 2011.

\section{B. Data analysis}

\section{Selection of recordings}

Given the mooring was not located in a summer concentration area where the migratory populations are seasonally segregated, peaks in vocal activity were examined to ensure that only the eastern Beaufort Sea population was transiting through the region (Garland et al., 2015). Previous work (Garland et al., 2015), identified the presence of beluga calls in the 291 days of recordings on the northeastern Chukchi mooring. Two peaks in vocal activity occurred in spring on this mooring; the first spring peak occurred from 23 April to 6 May and the second spring peak occurred from 18 May to 1 June (Garland et al., 2015). Results from satellitemonitored belugas, aerial surveys, and other acoustical studies indicate that both peaks likely corresponded to the eastern Beaufort Sea population migrating north through the northeastern Chukchi en route to their Canadian Beaufort summering grounds (Suydam, 2009; Delarue et al., 2011; Clarke et al., 2012; Hauser et al., 2014). The first spring peak spanning 14 days (April to May) was used in the current paper to ensure there was no interference from the eastern Chukchi Sea population, which follows the eastern Beaufort population out of the Bering Sea through the northeastern Chukchi later in the season (late June-early July; Suydam, 2009; Clarke et al., 2012; Hauser et al., 2014).

\section{Spectrographic analysis}

All 95-min recordings corresponding to the first peak in beluga detections (from 23 April to 6 May) were divided into 3-min sound files. All 3-min audio files containing calls (determined from Garland et al., 2015) were used in the current analysis to allow call classification. Recordings were examined (E.C.G.) in RAVEN PRO 1.4 (Bioacoustics Research Program, 2011) as smoothed spectrograms $11 \mathrm{~s}$ long with a 1024 point fast Fourier transform (FFT), Hanning window, $23 \mathrm{~Hz}$ resolution, and $75 \%$ overlap. Calls that were clearly distinguishable with a good signal-to-noise ratio (SNR) measuring at least $10 \mathrm{~dB}$ above background noise levels ("energy" measurement in RAVEN 1.4; in a 0.1 s slice covering the frequency range of the call), measured within $0.5 \mathrm{~s}$ immediately preceding or following a call (depending on surrounding calls), were used for this analysis. Calls were also graded on a subjective quality system from 1 (highest quality) to 5 (poor quality) following Chmelnitsky and Ferguson (2012). Calls that scored between 1 (excellent) and 3 (average) and also passed the $10 \mathrm{~dB}$ requirement were included in further analysis to ensure only the highest quality data was included in analysis. Because of the sampling rate limitation, acoustic properties of calls as well as whistles above $8 \mathrm{kHz}$ were not recorded; thus, our analysis is limited to the fundamental components of tonal signals as well as to harmonic components and broadband signals below $8 \mathrm{kHz}$. To ensure a variety of vocalizations were included in the analysis and to reduce bias toward days with a large volume of beluga calls, a maximum of 100 high quality calls were selected per day to be included in the analysis for days containing a large volume of beluga calls. These were the first 100 high quality calls for that day selected from the hour containing the highest quality and number of calls (e.g., sections containing a large number of calls and not sections containing a small number of isolated calls). This selection method maximized the number of days sampled and the quality of the calls selected. For days containing a small volume of calls, all 3-min audio files with identified beluga calls were examined.

\section{Subjective classification}

Sounds were initially classified subjectively through aural and visual matching of calls to call types following the classification scheme of Sjare and Smith (1986; see Table I). There were three levels to the classification system: vocalization family (i.e., whistle, pulse call, noisy call, combined call, or click), contour category (e.g., flat, modulated, ascending), and call type. Multiple call types could be included in a contour category, and multiple contours could be included in a vocalization family. For example, the individual call types of flat whistle and broken flat whistle were both part of the higher-level flat contour category and the whistle vocalization family. Call types were named using a short-hand naming system (Table I). The first part of the name indicated the vocalization family: a whistle (denoted with a "ws"), a pulse call (denoted with a "pulse"), or a combined call ("c"). For whistles, calls were further divided by contour which was noted preceding the "ws" (e.g., "dws" denoted a descending whistle while "nws" denoted a n-shaped whistle). The name also indicated if the whistle was broken (e.g., nws.seg) and if there was a particular arrangement to the number of breaks (e.g., nws.seg.b). For pulse calls, the contour (if present) was denoted with an "a" (ascending) or "d" (descending), depending on the direction (e.g., "pulse.I.a" for ascending pulse type I calls). Combined calls were numbered starting with one (i.e., c. 1 denotes combined call type 1).

Call type naming was based primarily on the contour of the fundamental frequency of calls. New contour categories added to the initial scheme of Sjare and Smith (1986) included (Table I): two u-shaped broken whistle (call type 5b) contours (call types uws.seg.c and d), a fourth modulated whistle (call type 6a) contour (s-shaped), and two pulsed call type I (pulsed tone) contour categories (pulse.I.a and pulse.I.d). Additional subdivision of existing contour categories presented in classification scheme of Sjare and Smith (1986) were also undertaken where a variation of a call was consistent (e.g., r-shaped whistle as a variant of call $2 \mathrm{a}$ ascending whistles). A full description of our classification 


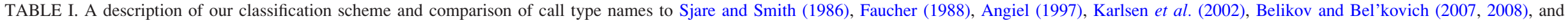
Chmelnitsky and Ferguson (2012). The two most common call types noted in each reference are included along with the percentage of total calls (in parentheses).

\begin{tabular}{|c|c|c|c|c|c|c|c|}
\hline \multicolumn{2}{|c|}{ Current study population } & \multicolumn{6}{|c|}{ Other studied populations } \\
\hline \multicolumn{2}{|c|}{ Eastern Beaufort Sea, USA/Canada } & Cunningham Inlet, Canada & Svalbard, Norway & White Sea, Russia & $\begin{array}{c}\text { Churchill River, } \\
\text { Canada }\end{array}$ & $\begin{array}{l}\text { Bristol Bay, } \\
\text { Alaska, USA }\end{array}$ & $\begin{array}{l}\text { St. Lawrence } \\
\text { Estuary, Canada }\end{array}$ \\
\hline Call type & Full name & Sjare and Smith (1986) & Karlsen et al. (2002) & Belikov and Bel'kovich $(2007,2008)$ & Chmelnitsky and Ferguson (2012) & Angiel (1997) & Faucher (1988) \\
\hline ahq & Ascending high squeak & $2 \mathrm{a}$ & $\mathrm{CT}-2 \mathrm{a}$ & - & - & - & CT2a \\
\hline aws & Ascending whistle & $2 \mathrm{a}$ & $\mathrm{CT}-2 \mathrm{a}$ & W9 & W2a, W2b & 1 & CT2a \\
\hline aws.seg & Broken ascending whistle & $2 b$ & - & - & - & - & СТ2b \\
\hline dhq & Descending high squeak & $4 a$ & CT-4a & W15 & - & - & CT4a \\
\hline dws $(11.87 \%)^{\mathrm{a}}$ & Descending whistle & $4 \mathrm{a}$ & CT-4a & W13, W14 & W3a, W3b, W3c & 6 & CT4a \\
\hline dws.seg & Broken descending whistle & $4 \mathrm{~b}$ & - & - & - & - & CT4b \\
\hline flatws & Flat whistle & $1 \mathrm{a}(9.3 \%)$ & CT-1a $(32.2 \%)$ & W4, W5 & W1a & $4(13.8 \%)$ & $\mathrm{CT} 1 \mathrm{a}^{\mathrm{b}}$ \\
\hline flatws.m $(8.93 \%)^{\mathrm{a}}$ & Mostly flat whistle & - & - & - & W1c $(7.9 \%)$ & 13 & - \\
\hline flatws.seg & Broken flat whistle & $1 \mathrm{~b}(10.5 \%)$ & CT-lb & w3 & W1b & 4 & $\mathrm{CT} 1 \mathrm{~b}^{\mathrm{b}}$ \\
\hline $\mathrm{hq}$ & High squeak & 1a & CT-1a & - & - & 4 & CT1a \\
\hline modws & Modulate whistle & $6 a$ & CT-6ab & W6, W7, w8 & W6a, w6b & 8 & СT6a \\
\hline modws.m & Messy modulated whistle & $6 \mathrm{~b}$ & CT-6ab & W10 & W6c & 3 & СТ6c \\
\hline modws.S & Short modulated whistle & - & - & - & W5d & 9 & - \\
\hline modws.seg & Broken modulated whistle & $6 c$ & CT-6c, CT-S2 & - & W4e & 5 & CT6b \\
\hline nws & $\mathrm{N}$-shaped whistle & $3 a$ & CT-3a & W11, W12 & W4a, W4b, W4c & $2,7,10$ & СТ3a \\
\hline nws.seg.b & Broken n-shaped whistle & $3 b$ & - & - & - & - & СТ3b \\
\hline nws.seg.c & Broken n-shaped whistle & $3 c$ & - & - & - & - & СТ3d \\
\hline nws.seg.d & Broken n-shaped whistle ${ }^{c}$ & $3 \mathrm{~d}$ & - & - & W4d & - & СТ $3 \mathrm{c}$ \\
\hline rws & R-shaped whistle & $2 \mathrm{a}$ & - & - & $\mathrm{W} 2 \mathrm{c}(10.3 \%)$ & 14 & - \\
\hline rws.seg & Broken r-shaped whistle & $2 b$ & - & - & - & - & - \\
\hline trill & Trill & 7 & CT-S1 & $\mathrm{W} 2^{\mathrm{b}}$ & W6d & 6 & $\mathrm{CT} 7$ \\
\hline uws & U-shaped whistle & $5 \mathrm{a}$ & CT-5a & $\mathrm{W} 1^{\mathrm{b}}$ & W5a, W5b & 15 & СТ5a \\
\hline uws.seg.b & Broken u-shaped whistle & $5 b$ & - & - & - & 5 & CT5b \\
\hline uws.seg.c & Broken u-shaped whistle & - & - & - & - & - & CT5b \\
\hline uws.seg.d & Broken u-shaped whistle & - & - & - & - & - & CT5b \\
\hline pulse.A & Type A-pulsed cries/screams & $\mathrm{A}, \mathrm{B}, \mathrm{C}$ & CT-I (13\%), CT-V & IPT5, IPT6 & P7 & 18,23 & Grp.2 \\
\hline pulse.I & Type I-pulsed tones & $\mathrm{H}, \mathrm{I}$ & CT-I, CT-V & IPT5, IPT6 & P1c & 26 & Grp.3 \\
\hline pulse.I.a & Type I-ascending pulsed tones & $\mathrm{H}, \mathrm{I}$ & CT-I, CT-V & - & $P 8^{\mathrm{d}}$ & - & - \\
\hline pulse.I.d & Type I-descending pulsed tones & $\mathrm{H}, \mathrm{I}$ & CT-I, CT-V & - & - & 20,29 & - \\
\hline noisy & Noisy & $\mathrm{D}$ & CT-III & $\mathrm{N} 3, \mathrm{~N} 4$ & $P 2^{\mathrm{d}}$ & - & Nois. \\
\hline click & Restricted frequency click series & $\mathrm{J} / \mathrm{K}$ & CT-II & $\mathrm{bIS} 2^{\mathrm{d}}$ & $\mathrm{P} 4$ & - & Restr.cl. \\
\hline c. 1 & Combo.1 & - & - & - & - & - & - \\
\hline c. 2 & Combo.2 & - & - & - & - & - & - \\
\hline c. 3 & Combo.3 & - & CT-A & - & $\mathrm{C} 2$ & 28 & - \\
\hline c. 4 & Combo.4 & - & - & - & - & - & - \\
\hline c. 5 & Combo.5 & - & CT-C & - & - & - & - \\
\hline c. 6 & Combo.6 & - & - & - & - & - & - \\
\hline
\end{tabular}

${ }^{\mathrm{a}}$ See Fig. 2.

O ${ }^{b}$ Listed as the two most common call types. Angiel (1997): call type 16-narrowband pulse call (9.63\%).

${ }^{\mathrm{c}}$ Call type not identified in current study.

${ }^{\mathrm{d}}$ Spectrogram difficult to compare. 
scheme and comparison of call type names to Sjare and Smith (1986), Faucher (1988), Angiel (1997), Karlsen et al. (2002), Belikov and Bel'kovich (2007, 2008), and Chmelnitsky and Ferguson (2012), is provided in Table I.

Given the highly vocal nature of belugas, overlapping calls (in time and frequency) may occur. Calls that were separated by $>0.2 \mathrm{~s}$ were considered separate calls (following Chmelnitsky and Ferguson, 2012). If a call was within $0.2 \mathrm{~s}$ of another, these were assigned as segments of a single, broken (segmented) call. To ensure this was indeed a call type and not simply an artifact of multiple animals calling at once, a broken call type was required to be observed at least three times. This quickly resolved whether the combination of various segments was indeed a single and stereotypic call type or multiple individual calls randomly produced at once by an unknown number of individuals.

\section{Quantitative classification and statistical analysis of call types}

In RAVEN, each beluga call was measured by isolating (in a "selection box") the sound for analysis. Measurements that were automatically generated by Raven included: duration, minimum and maximum frequency, bandwidth, and peak frequency (Table II). If there were any other calls within the overall selection box contributing to peak spectral energy, peak frequency was additionally measured by hand by sampling the call using a second, smaller selection box centered over the peak (3\% of calls). None of the other factors were impacted by other calls (e.g., from other species such as bearded seals, Erignathus barbatus) within the selection box. Further measurements were manually made which included (Table II): start and end frequency, ratio of the start to end frequency (frequency trend ratio), and ratio of the maximum to minimum frequency (frequency range ratio). A number of measurements were also directly extracted from the spectrogram view including: the number of inflections, the number of breaks for broken whistles (following Sjare and Smith, 1986), and the pulse repetition rate (PRR; measured using the harmonic interval following Watkins, 1967). The overall vocalization family (whistle, pulsed, noisy,

TABLE II. Description of measurements used in the quantitative classification of beluga call types. Variables measured on the fundamental frequency component.

\begin{tabular}{lcc}
\hline \hline Measurement & Abbreviation & Description \\
\hline Duration (s) & Dur & Length of call \\
Minimum frequency (Hz) & Min & Minimum frequency \\
Maximum frequency (Hz) & Max & Maximum frequency \\
Start frequency $(\mathrm{Hz})$ & Start & Start frequency \\
End frequency $(\mathrm{Hz})$ & End & End frequency \\
Bandwidth $(\mathrm{Hz})$ & BW & Max-Min frequency \\
Peak frequency (Hz) & Peak & Frequency of the spectral peak \\
Frequency range (ratio) & Range & Ratio of max/min frequency \\
Frequency trend (ratio) & Trend & Ratio of start/end frequency \\
Inflections (\#) & Inflec & Number of reversals in slope \\
Steps (\#) & Steps & Number of breaks \\
& & for broken whistles \\
Pulse repetition rate (/s) & PRR & For pulsed calls \\
\hline \hline
\end{tabular}

combined, or click) was noted, along with the qualitative name, and the qualitative classification according to Sjare and Smith (1986). To ensure a low level of subjective error in measurements, only the highest quality data were included in analysis. The number of harmonics present for each call has been included in previous studies (e.g., Belikov and Bel'kovich, 2007); however, given the limitations of our recording system $(8 \mathrm{kHz}$ limit), this measurement was not included.

Frequency measurements were taken on the fundamental component for harmonic sounds. For pulsed calls and noisy calls, the entire broadband signal was isolated in the selection box. The start and end frequencies of pulsed and noisy calls were recorded as the peak frequency if there was no slope (e.g., ascending or descending frequency components) to the call.

The measured variables were subjected to a nonparametric CART with cross-validation using the rpart package in $\mathrm{R}$ ( $\mathrm{R}$ Foundation for Statistical Computing, 2012), following the method of Garland et al. (2012) and Rekdahl et al. (2013). As we had no concurrent visual data to understand the number of animals within range of the recorder, multiple calls from an individual animal are likely included in the analysis. The 100 call limit per day, however, should assist in reducing pseudo-replication of individuals overall (assuming animals/groups on their spring migration continued moving northeast out of the range of the recorder). Regardless, CART analyses are robust to outliers, nonnormal, and non-independent (correlated) data (Breiman et al., 1984). Thus they are preferable to discriminant function analyses (DFA) and principal component analyses (PCA), which require independence of samples, normal distributions of discriminating variables, homogeneity of variances, linearity, and uncorrelated discriminating variables (see Rekdahl et al., 2013 for a detailed argument). Our data likely violate these assumptions simply due to the unknown level of pseudo-replication of calls per individual. All variables in CART are considered in each splitting decision in the classification tree, and the analysis is strengthened by correlated or co-linear variables (Breiman et al., 1984). Following the method of Garland et al. (2012) and Rekdahl et al. (2013), the classification tree was split into nodes based on the Gini index to reduce the impurity of nodes or "goodness of split" (Breiman et al., 1984). The terminal nodes were set to have a minimum sample size of ten given the sample size of most call types was larger than this. The tree was overgrown and cross-validation ( $\mathrm{V}$-fold cross-validation with 50 subsets) was performed. This was followed by upward pruning of the tree until the best predictive tree with the smallest estimated classification error was obtained (using the $1 \mathrm{SE}$ rule; see Breiman et al., 1984).

The measured variables were also subjected to a Random Forest analysis (Breiman, 2001) using the randomForest package in $\mathrm{R}$ (Liaw and Wiener, 2002). This extends standard CART analyses as it creates a collection of trees (i.e., a forest instead of a single tree), which are used to assess the classification uncertainty of each tree during construction [out-of-bag (OOB) error], and the overall importance of each predictor variable (i.e., measurements from 


\begin{tabular}{|c|c|c|c|c|c|c|c|c|c|c|c|c|}
\hline \multirow{2}{*}{$\begin{array}{l}\text { Call } \\
\text { type }\end{array}$} & \multirow{2}{*}{$\begin{array}{l}\text { Contour } \\
\text { type }\end{array}$} & \multirow[b]{2}{*}{$\mathrm{N}$} & \multirow{2}{*}{$\begin{array}{l}\% \text { total } \\
\text { calls }\end{array}$} & \multirow[b]{2}{*}{ Dur (s) } & \multicolumn{6}{|c|}{ Frequency $(\mathrm{Hz})$} & \multirow[b]{2}{*}{ Inflec } & \multirow[b]{2}{*}{ Step } \\
\hline & & & & & Min & $\operatorname{Max}$ & BW & Peak & Start & End & & \\
\hline ahq & & 18 & 1.77 & $0.08 \pm 0.02$ & $2268 \pm 750$ & $3136 \pm 1417$ & $868 \pm 1041$ & $2651 \pm 1059$ & $2268 \pm 750$ & $3136 \pm 1417$ & 0.00 & 0.00 \\
\hline aws & & 70 & 6.87 & $0.46 \pm 0.35$ & $1682 \pm 1017$ & $2219 \pm 982$ & $536 \pm 286$ & $1917 \pm 968$ & $1683 \pm 1017$ & $2219 \pm 982$ & 0.00 & 0.00 \\
\hline aws.seg & & 8 & 0.79 & $0.42 \pm 0.33$ & $2662 \pm 685$ & $3361 \pm 1078$ & $699 \pm 579$ & $2914 \pm 840$ & $2662 \pm 685$ & $3361 \pm 1078$ & 0.00 & $1.50 \pm 1.07$ \\
\hline rws & & 41 & 4.02 & $0.64 \pm 0.27$ & $2038 \pm 1323$ & $2420 \pm 1297$ & $382 \pm 199$ & $2326 \pm 1307$ & $2038 \pm 1323$ & $2564 \pm 1470$ & 0.00 & 0.00 \\
\hline rws.seg & & 14 & 1.37 & $0.74 \pm 0.29$ & $1973 \pm 951$ & $2551 \pm 898$ & $578 \pm 429$ & $2355 \pm 858$ & $1973 \pm 951$ & $2532 \pm 905$ & 0.00 & $2.43 \pm 1.87$ \\
\hline dws & & 121 & 11.87 & $0.47 \pm 0.23$ & $2628 \pm 1611$ & $3169 \pm 1571$ & $541 \pm 397$ & $2883 \pm 1598$ & $3169 \pm 1572$ & $2633 \pm 1609$ & 0.00 & 0.00 \\
\hline dws.seg & & 27 & 2.65 & $0.71 \pm 0.43$ & $2325 \pm 1301$ & $3234 \pm 1210$ & $909 \pm 546$ & $2796 \pm 1228$ & $3230 \pm 1215$ & $2324 \pm 1300$ & 0.00 & $1.37 \pm 0.74$ \\
\hline flatws & & 47 & 4.61 & $0.35 \pm 0.27$ & $2979 \pm 1511$ & $3054 \pm 1519$ & $75 \pm 17$ & $3011 \pm 1513$ & $3012 \pm 1511$ & $3010 \pm 1510$ & 0.00 & 0.00 \\
\hline flatws.m & & 91 & 8.93 & $0.51 \pm 0.30$ & $3036 \pm 1615$ & $3153 \pm 1616$ & $116 \pm 20$ & $3093 \pm 1614$ & $3101 \pm 1620$ & $3088 \pm 1617$ & $1.13 \pm 1.52$ & 0.00 \\
\hline flatws.seg & & 15 & 1.47 & $0.55 \pm 0.40$ & $3229 \pm 1583$ & $3335 \pm 1564$ & $106 \pm 50$ & $3273 \pm 1573$ & $3265 \pm 1586$ & $3280 \pm 1572$ & 0.00 & $1.67 \pm 1.54$ \\
\hline $\mathrm{hq}$ & & 73 & 7.16 & $0.07 \pm 0.02$ & $3119 \pm 1233$ & $3293 \pm 1288$ & $174 \pm 365$ & $3185 \pm 1242$ & $3190 \pm 1236$ & $3191 \pm 1240$ & $0.07 \pm 0.25$ & 0.00 \\
\hline modws & & 29 & 2.85 & $0.92 \pm 0.65$ & $2456 \pm 1778$ & $3048 \pm 1648$ & $591 \pm 498$ & $2701 \pm 1694$ & $2869 \pm 1736$ & $2794 \pm 1763$ & $4.03 \pm 1.76$ & 0.00 \\
\hline modws.m & & 35 & 3.43 & $0.85 \pm 0.42$ & $2677 \pm 1612$ & $3286 \pm 1612$ & $609 \pm 489$ & $2931 \pm 1587$ & $2978 \pm 1659$ & $2922 \pm 1554$ & $4.77 \pm 2.04$ & 0.00 \\
\hline modws.S & & 59 & 5.79 & $0.60 \pm 0.23$ & $2129 \pm 1352$ & $2811 \pm 1463$ & $681 \pm 513$ & $2418 \pm 1310$ & $2552 \pm 1535$ & $2456 \pm 1269$ & $2.00 \pm 0.00$ & 0.00 \\
\hline modws.seg & & 39 & 3.83 & $0.81 \pm 0.31$ & $2114 \pm 1412$ & $3153 \pm 1533$ & $1039 \pm 702$ & $2618 \pm 1504$ & $2603 \pm 1470$ & $2571 \pm 1393$ & $4.10 \pm 2.50$ & $2.28 \pm 1.07$ \\
\hline nws & & 45 & 4.42 & $0.53 \pm 0.27$ & $2460 \pm 1401$ & $3013 \pm 1476$ & $553 \pm 549$ & $2818 \pm 1470$ & $2554 \pm 1484$ & $2711 \pm 1357$ & $1.00 \pm 0.00$ & 0.00 \\
\hline nws.seg.b & & 8 & 0.79 & $0.62 \pm 0.31$ & $2734 \pm 1440$ & $3226 \pm 1420$ & $492 \pm 248$ & $2970 \pm 1361$ & $3017 \pm 1528$ & $2754 \pm 1419$ & $1.00 \pm 0.00$ & $2.00 \pm 0.00$ \\
\hline nws.seg.c & & 12 & 1.18 & $0.34 \pm 0.18$ & $2448 \pm 1470$ & $3505 \pm 1538$ & $1057 \pm 910$ & $2820 \pm 1471$ & $2677 \pm 1373$ & $2641 \pm 1486$ & $1.00 \pm 0.00$ & $1.00 \pm 0.00$ \\
\hline trill & & 23 & 2.26 & $0.86 \pm 0.31$ & $2479 \pm 1678$ & $2894 \pm 1716$ & $415 \pm 355$ & $2671 \pm 1675$ & $2611 \pm 1733$ & $2674 \pm 1657$ & 0.00 & $6.87 \pm 2.77$ \\
\hline uws & & 68 & 6.67 & $0.67 \pm 0.44$ & $2032 \pm 989$ & $2771 \pm 1192$ & $740 \pm 698$ & $2213 \pm 980$ & $2670 \pm 1235$ & $2588 \pm 1108$ & $1.00 \pm 0.00$ & 0.00 \\
\hline uws.seg.b & & 3 & 0.29 & $0.54 \pm 0.38$ & $1499 \pm 704$ & $2283 \pm 467$ & $784 \pm 700$ & $1813 \pm 597$ & $2110 \pm 718$ & $2269 \pm 458$ & $1.00 \pm 0.00$ & $2.00 \pm 0.00$ \\
\hline uws.seg.c & & 2 & 0.20 & $0.50 \pm 0.07$ & $3331 \pm 1484$ & $4398 \pm 392$ & $1066 \pm 1092$ & $3392 \pm 1539$ & $4328 \pm 293$ & $4274 \pm 566$ & $1.00 \pm 0.00$ & $1.00 \pm 0.00$ \\
\hline uws.seg.d & & 1 & 0.10 & 0.78 & 1240 & 1674 & 434 & 1328 & 1370 & 1602 & 1.00 & 4.00 \\
\hline
\end{tabular}

Call type nws.seg.d $\mathbf{m} \mathbf{m}$ not identified in current study.

FIG. 2. Descriptive statistics of whistles (means \pm SD) by contour type from the eastern Beaufort Sea beluga whale population. See Table I for full name descriptions. Schematic contours match spectral shape of each call type.

Table II). Random Forests estimate error internally so there is no need for additional cross-validation, and the splitting of nodes occurs using a specified number of predictors that are randomly selected instead of all the available variables at each split (Breiman, 2001). Based on the stability of the classification of uncertainty of each tree (lowest OOB error), the number of predictors randomly selected at a node for splitting was set to three, and 1000 trees were grown (following Rankin et al., 2013). The error per call type and the overall OOB error rate of the Forest were used to assess the overall success of classification.

\section{RESULTS}

\section{A. Subjective classification}

From the 1541 calls identified in the recordings (29\% of the 3-min files contained calls spread over 13 of the 14 days), 1019 calls were of a sufficient SNR and quality (1-3) to be used in further analysis. Thirty-six call types were identified subjectively based on the classification scheme suggested by Sjare and Smith (1986). These were divided into whistles (24 call types; Figs. 2 and 3), pulsed calls, clicks, and noisy calls (six call types; Table III, Fig. 4), and combined calls (six call types; Table IV, Fig. 5).

\section{Whistles}

Seven major whistle contour categories were identified. These were the flat, ascending, descending, n-shaped, u-shaped, modulated, and trilled whistles (Figs. 2 and 3; see Table I for call type names). Flat whistles were the most common contour category $(22.18 \%$ of total calls; flatws, flatws.m, flatws.seg, and hq) as it contained the second (flatws.m, $8.93 \%$ of total calls) and third (hq, $7.16 \%$ of total calls) most common call types. Descending whistles (dws) were the most common call type (11.87\% of total calls), which resulted in the descending whistle contour category being the second most common category $(16.88 \%$ of total calls; dws, dws.seg, dhq). This was closely followed by modulated $(15.90 \%$ of total calls; modws, modws.m, modws.S, modws.seg) and ascending whistles (14.82\% of total calls; aws, ahq, aws.seg, rws, rws.seg). U-shaped, $\mathrm{n}$-shaped, and trilled whistle contour categories were less common with $<10 \%$ of the total number of calls per category. We did not identify any highly broken $\mathrm{n}$-shaped whistles (nws.seg.d) included in classification system of Sjare and Smith (1986).

\section{Pulsed calls, clicks, and noisy calls}

Four main categories of pulsed calls were identified (Table III, Fig. 4; following Sjare and Smith, 1986). Pulse type I calls (pulsed tones) were the most common pulsed call (4.61\% of total calls) and included two additional call types: an ascending pulse type I call (pulse.I.a) and a descending pulse type I call (pulse.I.d). Pulse type A had a higher PRR and was more screamlike. Noisy calls were uncommon $(0.20 \%$ of total calls) as were restricted frequency click series $(0.29 \%$ of total calls).

\section{Combined calls}

Six combined call types were identified (Table IV, Fig. 5). Both c. 3 and c.6 contained two whistles within the call. c.5 was the most common combined call $(1.47 \%$ of total calls), followed by c.3, c.4, and c.6 (all $0.29 \%$ of total calls). 
Flat contour

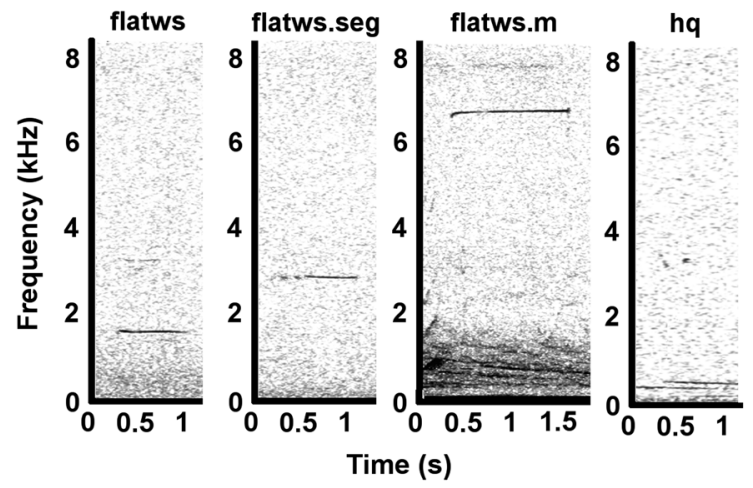

Descending contour

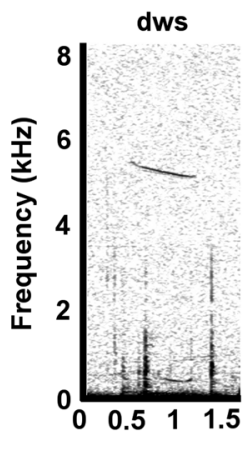

Trill contour

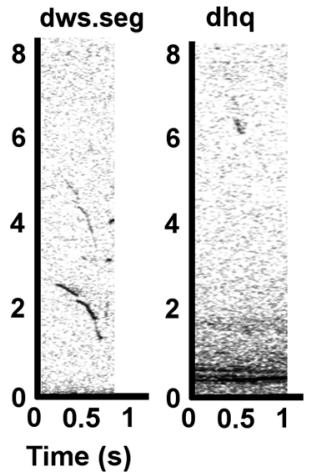

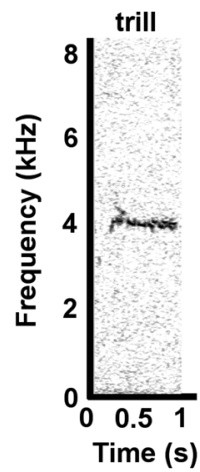

\section{Ascending \\ contour}
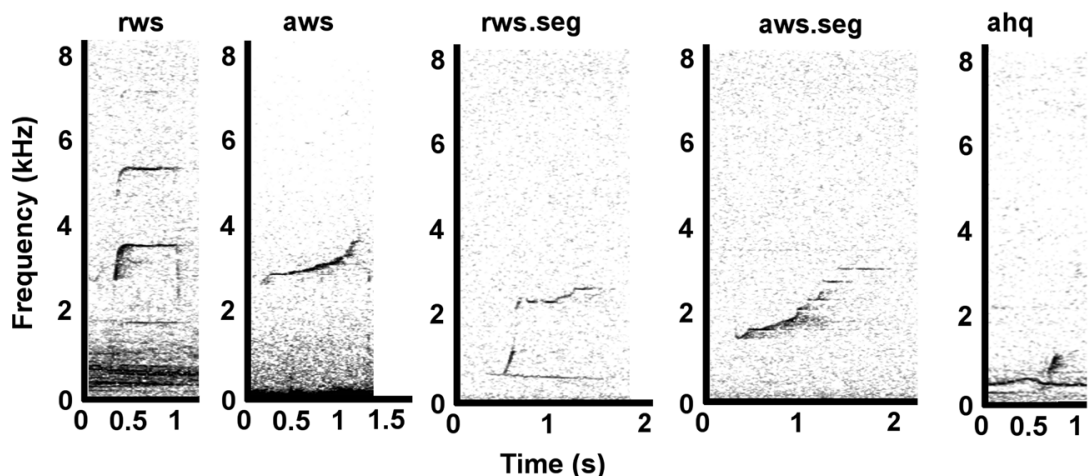

Modulated contour
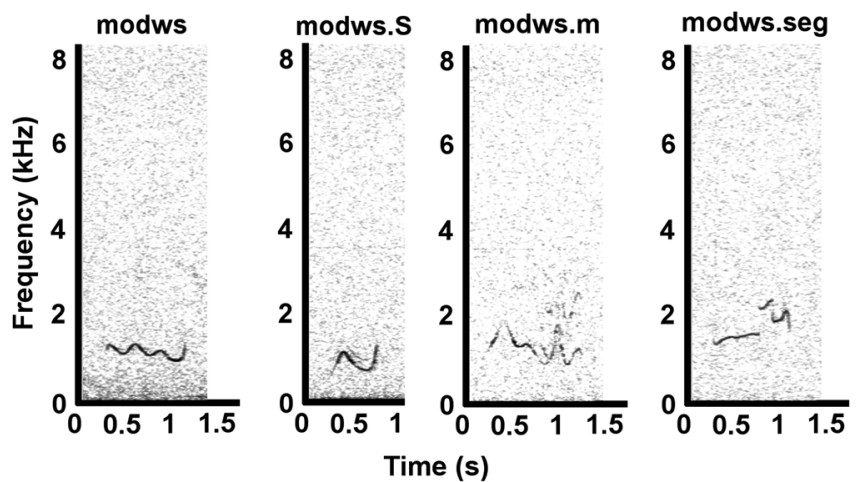

N-shaped contour
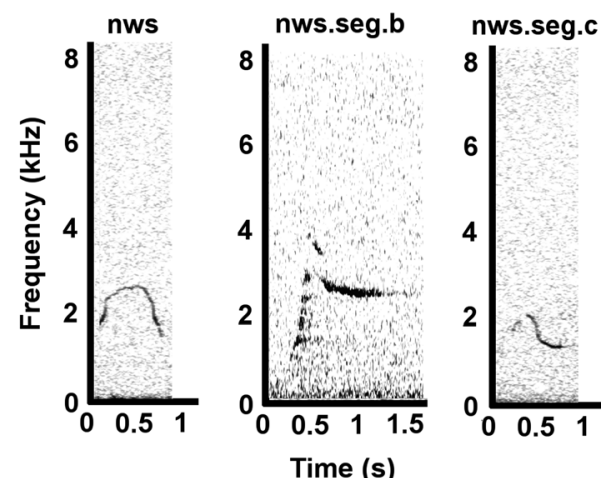

FIG. 3. Whistle contour categories based on Sjare and Smith (1986) and example call types from the eastern Beaufort Sea beluga whale population. Note the inclusion of two additional u-shaped broken whistle contour types (uws.seg.c and d), and a fourth modulated whistle contour (modws.S; s-shaped contour) not included in Sjare and Smith (1986). The hq call type spectrogram contains two high squeaks. Bearded seal trills are present in a number of spectrograms below $2 \mathrm{kHz}$. Spectrograms were 1024 point fast Fourier transform (FFT), Hanning window, $23 \mathrm{~Hz}$ resolution, and $75 \%$ overlap, generated in RAVEN PRO 1.4 with the same aspect ratio. See Table I for full name descriptions.

\section{B. CART}

Whistles, pulsed calls, noisy calls, restricted frequency clicks, and combined calls were included in a single analysis with all measured variables. The u-shaped broken whistle call types (uws.seg.b, uws.seg.c, and uws.seg.d) were combined into a single call type (uws.seg) for the statistical analyses (due to small sample size), which resulted in 34 call types included. All variables from Table II were available for tree construction; the variables CART utilized in tree construction (in decreasing order of use for splitting the tree) were the number of breaks (steps; seven splits), pulse repetition rate (PRR; six splits), bandwidth (BW; four splits), duration (Dur; four splits), the number of inflections (Inflec; four splits), frequency trend (trend; three splits), maximum frequency (max; two splits), start frequency (start; two splits), and peak frequency (peak; one split). These variables provided the analysis with $88.13 \%$ classification of call types (root node error) and correctly classified over $83 \%$ of calls. Thirty-four terminal nodes were created from the 34 call types (Fig. 6); the first branch in the tree was based on bandwidth, which separated out the flat whistles. Branching did 
TABLE III. Descriptive statistics of pulsed and noisy calls (means \pm SD) from the eastern Beaufort Sea beluga whale population.

\begin{tabular}{|c|c|c|c|c|c|c|c|c|c|c|c|c|}
\hline \multirow[b]{2}{*}{ Call type } & \multirow{2}{*}{$\mathrm{N}$} & \multirow{2}{*}{$\begin{array}{c}\text { Percent } \\
\text { total calls }\end{array}$} & \multirow[b]{2}{*}{ Duration (s) } & \multicolumn{6}{|c|}{ Frequency $(\mathrm{Hz})$} & \multirow[b]{2}{*}{ Inflection } & \multirow[b]{2}{*}{ Step } & \multirow[b]{2}{*}{ PRR } \\
\hline & & & & Minimum & Maximum & BW & Peak & Start & End & & & \\
\hline click & 3 & 0.29 & $1.72 \pm 1.60$ & $2794 \pm 223$ & $5714 \pm 876$ & $2920 \pm 949$ & $4565 \pm 226$ & $4565 \pm 226$ & $4565 \pm 226$ & 0.00 & $2.00 \pm 3.46$ & $68 \pm 66$ \\
\hline noisy & 2 & 0.20 & $0.76 \pm 0.78$ & $1309 \pm 465$ & $4925 \pm 4471$ & $3616 \pm 4936$ & $1344 \pm 498$ & $4425 \pm 3764$ & $4362 \pm 3853$ & 0.00 & 0.00 & N/A \\
\hline pulse.A & 22 & 2.16 & $0.99 \pm 0.29$ & $2512 \pm 1399$ & $4404 \pm 2115$ & $1892 \pm 2143$ & $3353 \pm 1546$ & $3371 \pm 1474$ & $3426 \pm 1355$ & $0.95 \pm 1.36$ & 0.00 & $240 \pm 309$ \\
\hline pulse.I & 47 & 4.61 & $0.85 \pm 0.42$ & $3756 \pm 2046$ & $4757 \pm 2177$ & $1001 \pm 895$ & $4226 \pm 2200$ & $4225 \pm 2179$ & $4220 \pm 2217$ & $0.51 \pm 0.86$ & $0.06 \pm 0.32$ & $98 \pm 28$ \\
\hline pulse.I.a & 16 & 1.57 & $0.86 \pm 0.33$ & $3335 \pm 1336$ & $4704 \pm 1423$ & $1369 \pm 312$ & $3988 \pm 1594$ & $3342 \pm 1327$ & $4432 \pm 1243$ & 0.00 & $0.06 \pm 0.25$ & $113 \pm 57$ \\
\hline pulse.I.d & 30 & 2.94 & $0.76 \pm 0.30$ & $2066 \pm 966$ & $3876 \pm 897$ & $1809 \pm 871$ & $2889 \pm 973$ & $3363 \pm 886$ & $2130 \pm 1039$ & $0.07 \pm 0.25$ & $0.03 \pm 0.18$ & $163 \pm 86$ \\
\hline
\end{tabular}

not follow vocalization family. Instead branching was heavily influenced by call contour as different branches represent the majority of the call types in each contour category (e.g., ascending, descending). This resulted in a few instances of vocalizations (e.g., pulsed vocalizations) being repeated in different terminal nodes; the PRR variable was utilized closer to terminal nodes and not as a high-level splitting variable. As a result, instead of a single pulsed vocalization family branch within the tree, the pulse.I.a call type was placed within the ascending call contour branch, while the pulse.I.d call type was part of the descending contour branch. Differences in bandwidth and duration also indicate the (subjective) classification of ascending whistles (call type aws)

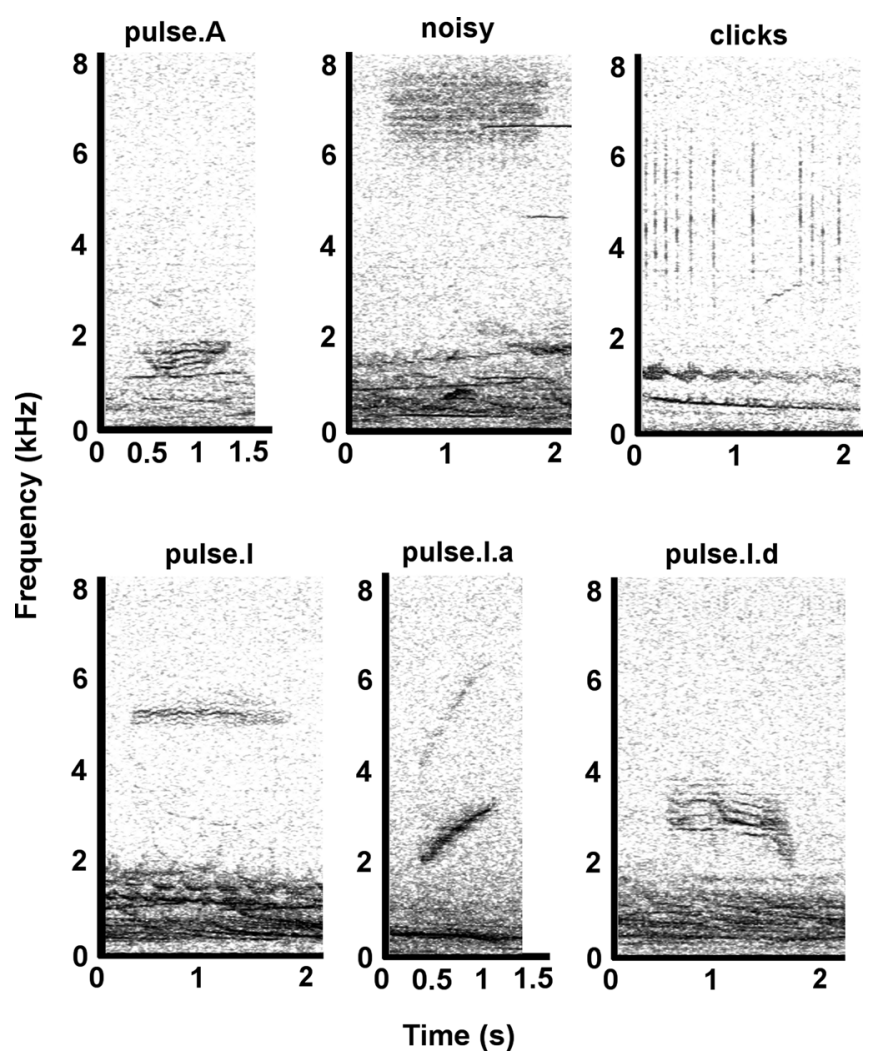

FIG. 4. Example pulsed calls, noisy call, and restricted frequency clicks from the eastern Beaufort Sea beluga whale population, based on the classification scheme of Sjare and Smith (1986). Note the addition of two pulsed call type I contour categories (ascending pulse type I: pulse.I.a and descending pulse type I: pulse.I.d) not included in Sjare and Smith (1986). Most spectrograms include bearded seal trills below $2 \mathrm{kHz}$. Spectrograms were 1024 point FFT, Hanning window, $23 \mathrm{~Hz}$ resolution, and $75 \%$ overlap, generated in RAVEN PRO 1.4 with the same aspect ratio. could be further subdivided, as well as n-shaped whistles (call type nws) based on differences in peak and start frequencies.

\section{Random Forest analysis}

The Random Forest analysis correctly classified most beluga calls (OOB error rate $=16.78 \%$; Appendix, Table V). The most important variables were frequency trend and the number of inflections (mean decrease in Gini index $=139$ and 138, respectively), followed by duration (mean decrease in Gini index = 127) and bandwidth (mean decrease in Gini index $=119$; Appendix, Table VI). The majority of misclassifications compared to subjective classification occurred within contour categories (e.g., between ascending whistles such as aws and rws or between single inflection whistles such as nws and uws). Call types with a small number of examples (e.g., c.1, c.2, c.3, and noisy) had a high misclassification rate that increased the measure of error. Overall the Random Forest analysis was able to discriminate 34 call types with a low degree of error.

\section{DISCUSSION}

Call types from the eastern Beaufort Sea beluga population recorded during their spring migration were divided into 36 subjective call type categories, which were then readily classified into 34 different quantitative categories using CART and Random Forest analyses. This study provides the first baseline description of the call repertoire for the eastern Beaufort Sea beluga population and is the first study to describe the vocal repertoire of a beluga population using a robust and repeatable methodology. We report results here as a first description of the repertoire because our dataset would not allow description of a complete vocal repertoire due to the potentially limited behavioral contexts that might occur along a migratory corridor, the upper frequency limit of our recording system $(8 \mathrm{kHz})$, and the unknown proportion of belugas from this population that might have contributed to our call pool.

\section{A. Difficulties in classifying a graded call system}

A graded structure in vocal repertoires was first described decades ago for pilot whales (Globicephala melaena; Busnel and Dziedzic, 1966; Taruski, 1979) and killer whales (Bain, 1986; Ford, 1989), both of which are highly social and use a diverse call repertoire similar to belugas 


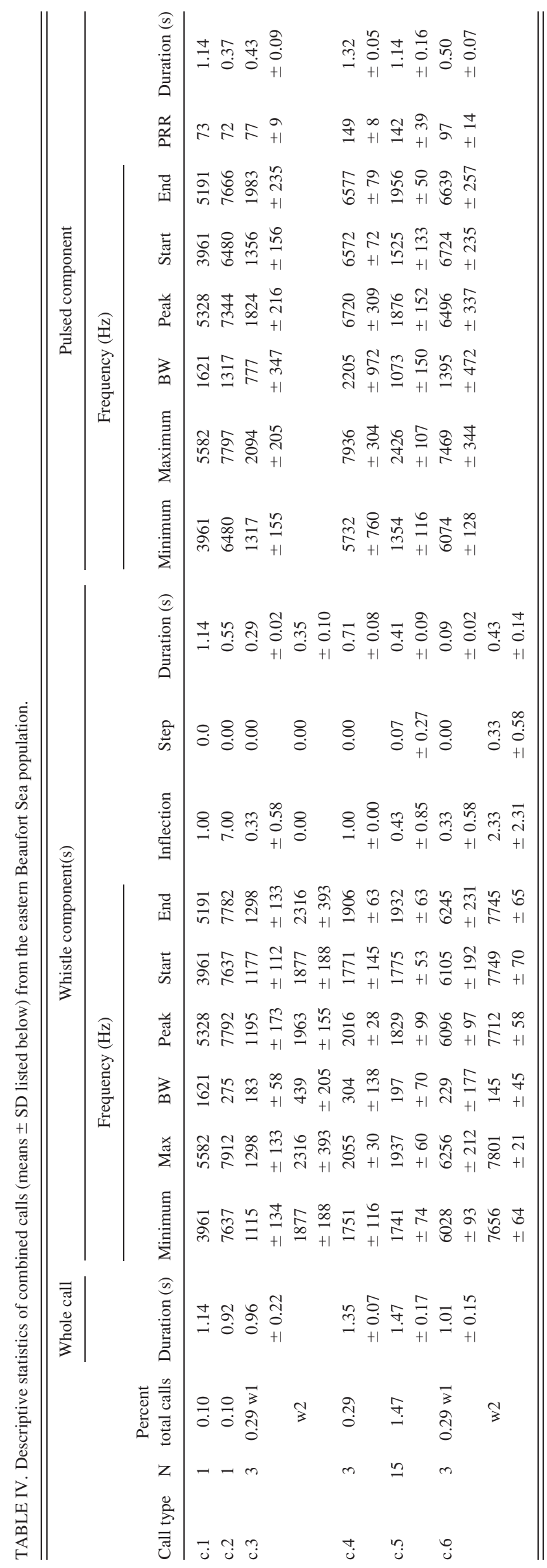

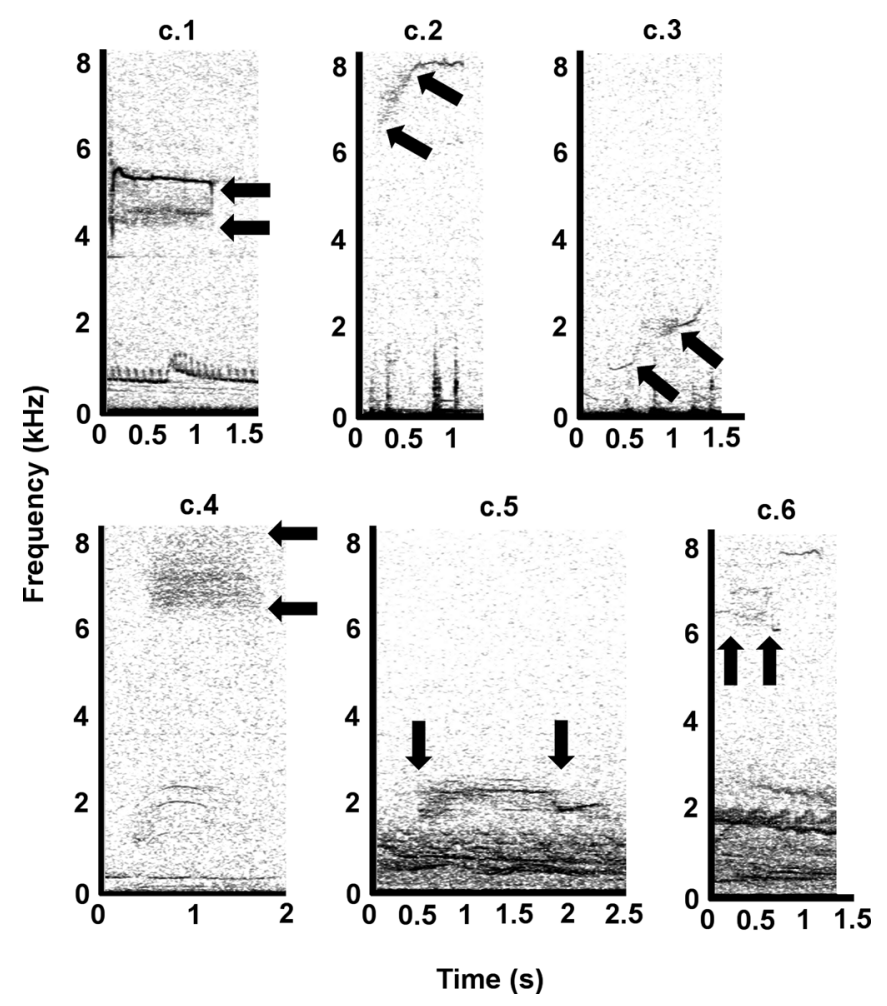

FIG. 5. Example combined call types from the eastern Beaufort Sea beluga whale population. Combined calls are composed of whistle and pulsed call components. The pulsed call component of each call is located between the arrows. Note c.1, c.5, and c.6 contain bearded seal trills below $2 \mathrm{kHz}$. Spectrograms were 1024 point FFT, Hanning window, $23 \mathrm{~Hz}$ resolution, and $75 \%$ overlap, generated in RAVEN PRO 1.4 with the same aspect ratio.

(Sjare and Smith, 1986; Faucher, 1988; Karlsen et al., 2002). Additional studies have shown that this graded vocal structure is common in other cetaceans (e.g., southern right whales Eubalaena australis, false killer whales Pseudorca crassidens, humpback whales; Clark, 1982; Murray et al., 1998; Dunlop et al., 2007) and a number of terrestrial groups (e.g., primates: red colobus monkeys Colobus badius; birds: least sandpiper Calidris minutilla, Patagonian black oystercatcher Hematopus ater; Marler, 1970; Miller, 1979). This produces major difficulties in creating discrete categories of call types. Previous work on belugas and other cetaceans has indicated the drawbacks with undertaking cluster analyses, DFAs, and PCAs to classify call types due to issues with auto-correlated variables (see Karlsen et al., 2002; Dunlop et al., 2007; Rekdahl et al., 2013). Here we have applied two powerful non-parametric classification methods, CART and Random Forests, which are able to incorporate and are actually strengthened by correlated variables. Both methods were able to classify call types based on 12 measured variables and produced 34 different call types. Agreement with the initial subjective classification of calls was high $(83 \%$ agreement for both statistical methods). This is comparable to similar studies on call type classification using CART ( $81 \%$ for humpback whale social sounds, Rekdahl et al., 2013; 88\% for humpback whale song units, Garland et al., 2012). Based on the high agreement in classification and the underlying assumptions being met, CART and Random Forest analyses should be used in preference to cluster 


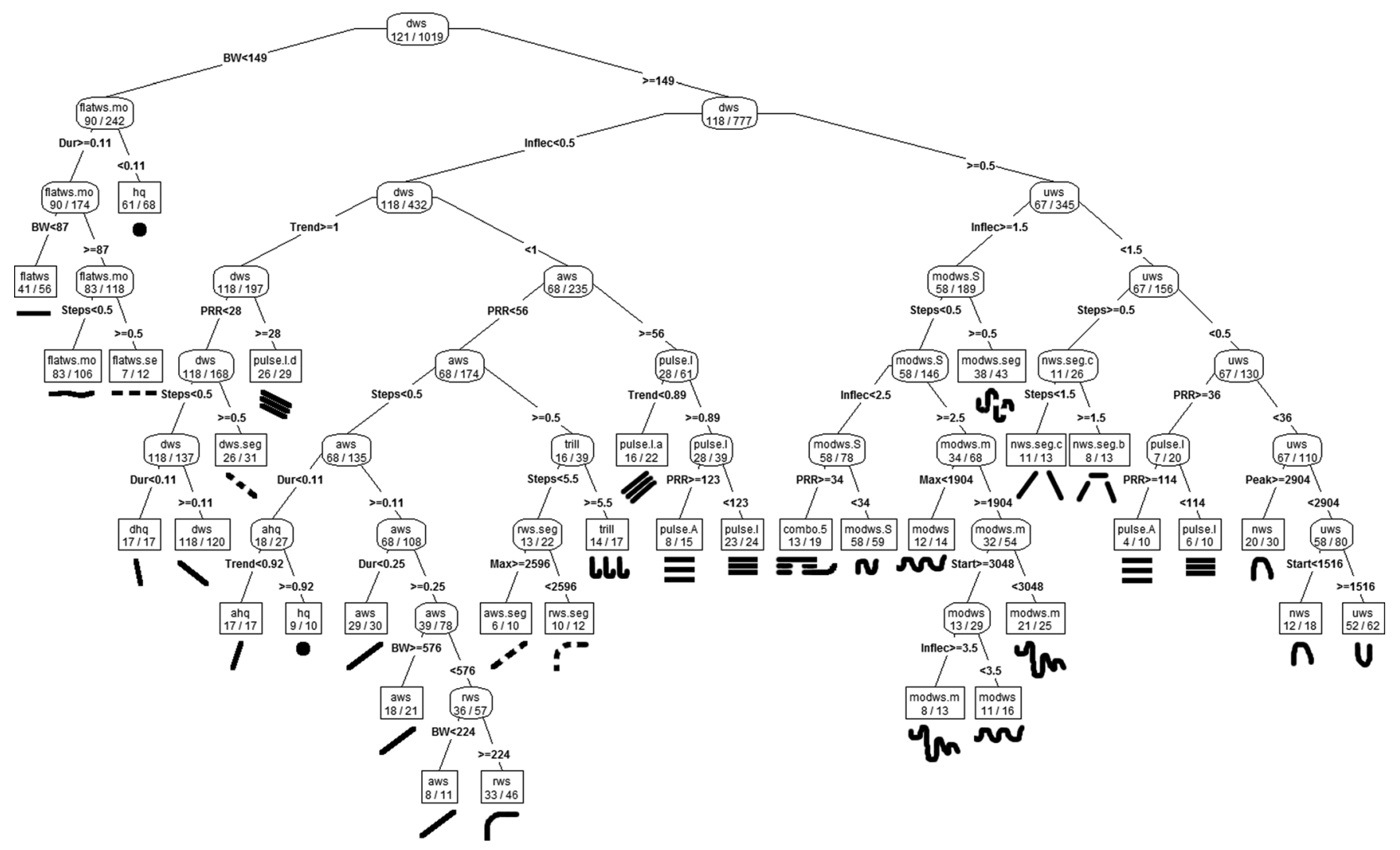

FIG. 6. Classification and regression tree (CART) of eastern Beaufort Sea beluga calls. The variables used at each split in the tree are listed, along with the criteria $(<,>$, or $=)$. Circle nodes display the number of calls to be split (right), and the number (left) and name of the call type with the highest number of calls (e.g., ahq 18/27). The terminal node boxes display the total number of correct classifications (below the call type), and the call type schematic contour below the box. This contour represents the general spectrographic shape of the call category. Repeated contours in different terminal node boxes imply similar call shape but with different acoustic parameters. Abbreviations of call type names can be found in Table I, and abbreviations of variables can be found in Table II.

analyses, DFAs, and PCAs in the classification of beluga and other delphinid vocalizations.

The Random Forest analysis had an overall classification error rate of $17 \%$, comparable with the $28 \%-30 \%$ for detections of tropical dolphins (Rankin et al., 2013). The majority of misclassifications compared to subjective classification occurred within contour categories (e.g., between ascending whistles such as aws and rws or between single inflection whistles such as nws and uws). Discrimination of subtle differences in similar call types may therefore be more challenging to identify with this analysis or alternatively may require additional variables to be included in the analysis (see following text) to allow fine-scale differentiation. Call types with a small number of examples (e.g., c.1, c.2, c.3, and noisy) also had a high misclassification rate that increased the measure of error. These could have been removed from the analysis to substantially lower the misclassification rate; however, our aim was to provide a statistical analysis that could capture the variability and differences among all measured beluga vocalizations not just whistles or those calls that were easily categorized. To improve classification within these categories in future analyses, we suggest that an additional measurement, time to maximum frequency (measured in seconds) should be added. This can also be converted to a proportion (time to maximum frequency/duration), if required. This should assist in discriminating the contour at a finer scale to allow differentiation, particularly between $\mathrm{n}$ - and $\mathrm{u}$-shaped whistles. Random Forest analyses are applicable and appealing to classification tasks from a wide array of species due to their robustness, their ability to calculate error internally, and by providing an understanding of the overall importance of each predictor variable (Breiman, 2001).

The CART analysis also misclassified $17 \%$ of calls compared to subjective classification. This misclassification rate was elevated due to the inclusion in the analysis of call types with less than ten calls $(N<10)$. The terminal nodes were set to have a minimum final size of ten (as this was smaller than most call type sample sizes), which resulted in 38 calls (4\% of all calls) being immediately misclassified. We wished to include all calls to provide a robust test of this method using difficult to classify graded calls and smaller sample sizes. Further, the analyses were run including whistles, pulsed calls, noisy calls, restricted frequency clicks, and combined calls, instead of on a subset of whistles (Chmelnitsky and Ferguson, 2012). This resulted in a very interesting tree that at first glance may be counter-intuitive (Fig. 6); for example, pulsed vocalizations were split into call types that were subsequently placed in different branches. One might expect that all pulsed vocalizations might occupy a single, large branch with multiple terminal nodes representing a number of pulsed call types. However, the resulting tree structure 
produced major branches based on call contour; ascending pulsed calls (i.e., pulse.I.a) were placed with ascending whistles (i.e., aws) in a large ascending call contour branch. Utilizing all available variables, CART indicated that grouping calls into major contour categories provided the best overall predictive tree with the smallest classification error. The initial subjective classification divided each call type (e.g., flatws) into three finer scale call types based on frequency bins $($ low $=0-2 \mathrm{kHz}, \operatorname{mid}=2-4 \mathrm{kHz}$, and high $=4-8 \mathrm{kHz}$ ). Using this highly divided classification system, CART was able to discriminate $95 \%$ of call types using the 12 variables but resulted in $26 \%$ misclassification given the inclusion of many call types with smaller sample sizes $(N<10$; data not shown). Given that this highly divided classification system resulted in a higher misclassification rate and also exceeded the upper limit for the number of categories in Random Forest analysis, it was not used in the current study. However, this sort of highly divided categorization system may be useful in the future for investigating fine-scale differences in call types or calling behavior within and between populations. CART analyses provided a robust classification method with an easy to interpret and visually appealing tree output displaying the splitting variable and criteria for each division in the tree. The exclusion of harmonics in classification (Belikov and Bel'kovich, 2007) was warranted due to the frequency limitation and did not appear to hamper classification by CART or Random Forest.

Data obtained from passive acoustic monitoring typically do not include information regarding the individual vocalizing within a group. This will result in a number of calls produced from an unknown number of individuals that therefore cannot be assigned to an individual. If all calls are included in analyses, this results in the pseudo-replication of calls from individuals that are not taken into account with standard DFA and PCA analyses. Non-parametric classification analyses such as CART or Random Forest should be used in preference to standard DFA and PCA analyses when using data of this type, regardless of the species or environment (terrestrial or marine) to ensure the data do not violate assumptions and thus invalidate or provide unrepresentative results.

\section{B. Comparison of call types with other known repertoires}

Worldwide, beluga call repertoires appear to be dominated by flat whistles. The most common call types from the Cunningham Inlet (Canada) repertoire presented in Sjare and Smith (1986) were a broken flat whistle (10.5\% of calls; Table I), followed by flat whistles ( $\sim 9 \%$ of calls). The repertoire analysis of belugas from Svalbard, Norway, by Karlsen et al. (2002) was dominated by a flat whistle call type (32.2\% of all calls). Flat whistles were also the most common call type in the repertoire of the Bristol Bay, Alaska, population (13.8\%; Angiel, 1997), and the St. Lawrence (Canada) population (Faucher, 1988). In the current study, mostly flat whistles (flatws.m) were the second most common call type (8.9\% of total calls; Table I and Fig. 2). Mostly flat whistles were also the second most common call type (7.9\% of total calls) in a repertoire analysis of Churchill River (Canada) beluga (Chmelnitsky and Ferguson, 2012).

For those repertoires where the flat whistle was not the predominant call type (i.e., Churchill River, Canada; White Sea, Russia; and the eastern Beaufort Sea belugas), the dominant call type was still a whistle, although the whistle type was unique for each repertoire. Descending whistles (dws) were the most common call type identified in the current study (11.9\% of total calls; Fig. 2). The most common call type identified by Chmelnitsky and Ferguson (2012) in the Churchill River repertoire (10.3\% of total calls) resembles our r-shaped whistle (rws), while the most common call type of White Sea (Russia) belugas were v-shaped whistles (Table I; Belikov and Bel'kovich, 2007).

Six distinct combined call types were identified for the eastern Beaufort Sea repertoire (Table IV). This is comparable to the six and seven combined calls identified in Svalbard and the Churchill River, respectively (Karlsen et al., 2002; Chmelnitsky and Ferguson, 2012). Although there are many differences among the Churchill River and Svalbard repertoires and the current study, some call types appear similar (Table I) and components of the combined call types are shared (e.g., the second whistle component present in combined calls in the current and Churchill River study; Chmelnitsky and Ferguson, 2012).

If we examine the overall contribution of pulsed and noisy calls to a repertoire, the Norwegian repertoire was dominated by pulsed and noisy calls (31.4\% of total calls; Karlsen et al., 2002). Pulsed and noisy calls comprised 21.5\% of the Cunningham Inlet repertoire (Sjare and Smith, 1986) and $25.9 \%$ of the Churchill River repertoire (Chmelnitsky and Ferguson, 2012), whereas pulsed and noisy calls represented $11.5 \%$ of the total calls recorded in the current study.

Pulsed calls are typically emitted more often during social interactions and are hypothesized to function in intragroup (short-range) communication (Faucher, 1988; Panova et al., 2012). Recordings of the Norwegian repertoire were taken from a small boat drifting close to the animals, which may have affected their behavior (Karlsen et al., 2002). Our recordings were taken while the animals were suggested to be migrating en route to their summer concentration areas. We have no concurrent visual data to confirm the behavioral state of the vocalizing animals; studies of behavioral state and call type suggest that simple, stereotyped tonal whistles are more likely to be used in long-range communication and are assumed to be involved in group coordination (Panova et al., 2012). The lower number of pulsed calls and higher percentages of whistles found in the current study may have occurred if the animals were engaged more in maintaining contact (longer-range communication) while migrating rather than engaging in social interactions. Alternatively, this ratio of pulsed calls to whistles may be a feature of the eastern Beaufort Sea population's repertoire. Further, the current study has a number of shared and novel combined call types, which adds weight to the idea of geographic variation in call types within this species. Future work is required to quantify how the various factors contribute to differences in beluga vocal repertoires, and such work 
should be cautious when generalizing across studies due to the confounding nature of these factors.

The current study indicates that overall for eastern Beaufort belugas there are seven major contour categories for whistles, four pulsed/noisy call categories, and a number of combined call types. The comparison of beluga call types among published studies is currently hindered due to a lack of standardization and robust quantitative analyses. We have presented a robust set of methods which excel at the classification of graded calls and should be adopted in the classification of beluga calls to allow a standardized comparison of results.

\section{Conclusions}

We have presented a description of the vocal repertoire of the eastern Beaufort Sea beluga population during its spring migration, which provides a baseline against which the call repertoire of other seasonally sympatric Alaskan beluga populations can be compared to investigate population structure. It employed two robust classification methods, CART and Random Forest, which paralleled the results obtained through manual visual and aural (subjective) classification of vocal repertories. Differences in populationspecific vocal repertoires have the potential to allow sympatric populations to be differentiated (similar to other delphinid species; see Papale et al., 2014), which will aid in the assessment of human impact (such as noise or oil spills) to a discrete population level. The robust set of analyses presented here provides a standardized set of methods that creates a set of quantitatively assigned call types that should allow the comparison of repertoires among geographic regions and should be utilized in future studies. Finally, these analytical methods should be undertaken instead of the traditional DFA, PCA, and cluster analyses for classification of any passively recorded calls for any species, where the number of calls per individual included in the analysis is unknown.

\section{ACKNOWLEDGMENTS}

The authors thank Phil Clapham, Sue Moore, Melinda Rekdahl, and Jessica Crance for providing comments on a previous version of this manuscript and Stephanie Grassia for creating the map. We thank Charles Monnett and Heather Crowley at the Bureau of Ocean Energy Management for their project support, and the captains and crew of both the $F V$ Alaskan Enterprise and FV Mystery Bay. Funding was provided by the Bureau of Ocean Energy Management under InterAgency Agreement M09PG00016. E.C.G. was supported by a National Research Council (National Academy of Sciences) Postdoctoral Fellowship. The findings and conclusions in this paper are those of the authors and do not necessarily represent the views of the National Marine Fisheries Service.

\section{APPENDIX}

TABLE V. Random Forest confusion matrix and classification error for each eastern Beaufort Sea beluga call type. The overall error rate in classification (OOB) was $16.78 \%$. Initial (subjective) call type names are listed in column 1. Subsequent columns list the number of each call type the initial call types were classified into by the Random Forest analysis. The call type (class) error rate (proportion) is listed in the final column.

\begin{tabular}{|c|c|c|c|c|c|c|c|c|c|c|c|c|c|c|c|c|c|c|}
\hline Call type & ahq & aws & aws.seg & click & c. 1 & c. 2 & c. 3 & c. 4 & c. 5 & c. 6 & dhq & dws & dws.seg & flatws & flatws.m & flatws. seg & $\mathrm{hq}$ & Call type error \\
\hline ahq & 18 & 0 & 0 & 0 & 0 & 0 & 0 & 0 & 0 & 0 & 0 & 0 & 0 & 0 & 0 & 0 & 0 & 0.000 \\
\hline aws & 0 & 57 & 0 & 0 & 0 & 0 & 0 & 0 & 0 & 0 & 0 & 0 & 0 & 0 & 1 & 0 & 0 & 0.186 \\
\hline aws.seg & 0 & 0 & 4 & 0 & 0 & 0 & 0 & 0 & 0 & 0 & 0 & 0 & 0 & 0 & 0 & 1 & 0 & 0.500 \\
\hline click & 0 & 0 & 0 & 0 & 0 & 0 & 0 & 0 & 0 & 0 & 0 & 0 & 0 & 0 & 0 & 0 & 1 & 1.000 \\
\hline c. 1 & 0 & 0 & 0 & 0 & 0 & 0 & 0 & 0 & 0 & 0 & 0 & 0 & 0 & 0 & 0 & 0 & 0 & 1.000 \\
\hline c. 2 & 0 & 0 & 0 & 0 & 0 & 0 & 0 & 0 & 0 & 1 & 0 & 0 & 0 & 0 & 0 & 0 & 0 & 1.000 \\
\hline c. 3 & 0 & 0 & 0 & 0 & 0 & 0 & 0 & 0 & 1 & 0 & 0 & 0 & 0 & 0 & 0 & 0 & 0 & 1.000 \\
\hline c. 4 & 0 & 0 & 0 & 0 & 0 & 0 & 0 & 3 & 0 & 0 & 0 & 0 & 0 & 0 & 0 & 0 & 0 & 0.000 \\
\hline c. 5 & 0 & 0 & 0 & 0 & 0 & 0 & 0 & 0 & 15 & 0 & 0 & 0 & 0 & 0 & 0 & 0 & 0 & 0.000 \\
\hline c. 6 & 0 & 0 & 0 & 0 & 0 & 0 & 0 & 0 & 0 & 3 & 0 & 0 & 0 & 0 & 0 & 0 & 0 & 0.000 \\
\hline dhq & 0 & 0 & 0 & 0 & 0 & 0 & 0 & 0 & 0 & 0 & 23 & 0 & 0 & 0 & 0 & 0 & 1 & 0.042 \\
\hline dws & 0 & 0 & 0 & 0 & 0 & 0 & 0 & 0 & 0 & 0 & 0 & 118 & 0 & 0 & 3 & 0 & 0 & 0.025 \\
\hline dws.seg & 0 & 0 & 0 & 0 & 0 & 0 & 0 & 0 & 0 & 0 & 0 & 1 & 26 & 0 & 0 & 0 & 0 & 0.037 \\
\hline flatws & 0 & 0 & 0 & 0 & 0 & 0 & 0 & 0 & 0 & 0 & 0 & 0 & 0 & 45 & 2 & 0 & 0 & 0.043 \\
\hline flatws.m & 0 & 0 & 0 & 0 & 0 & 0 & 0 & 0 & 0 & 0 & 0 & 1 & 0 & 3 & 84 & 0 & 1 & 0.077 \\
\hline flatws.seg & 0 & 0 & 0 & 0 & 0 & 0 & 0 & 0 & 0 & 0 & 0 & 0 & 0 & 0 & 1 & 12 & 0 & 0.200 \\
\hline $\mathrm{hq}$ & 0 & 0 & 0 & 0 & 0 & 0 & 0 & 0 & 0 & 0 & 0 & 0 & 0 & 2 & 0 & 0 & 70 & 0.041 \\
\hline modws & 0 & 0 & 0 & 0 & 0 & 0 & 0 & 0 & 0 & 0 & 0 & 0 & 0 & 0 & 1 & 0 & 0 & 0.414 \\
\hline modws.m & 0 & 0 & 0 & 0 & 0 & 0 & 0 & 0 & 0 & 0 & 0 & 0 & 0 & 0 & 0 & 0 & 0 & 0.286 \\
\hline modws.S & 0 & 0 & 0 & 0 & 0 & 0 & 0 & 0 & 0 & 0 & 0 & 0 & 0 & 0 & 1 & 0 & 0 & 0.017 \\
\hline modws.seg & 0 & 0 & 0 & 0 & 0 & 0 & 0 & 0 & 0 & 0 & 0 & 0 & 0 & 0 & 0 & 0 & 0 & 0.000 \\
\hline noisy & 0 & 0 & 0 & 0 & 0 & 0 & 0 & 0 & 0 & 0 & 0 & 0 & 0 & 0 & 0 & 0 & 0 & 1.000 \\
\hline nws & 0 & 0 & 0 & 0 & 0 & 0 & 0 & 0 & 0 & 0 & 0 & 0 & 0 & 0 & 4 & 0 & 0 & 0.489 \\
\hline nws.seg.b & 0 & 0 & 0 & 0 & 0 & 0 & 0 & 0 & 0 & 0 & 0 & 0 & 0 & 0 & 0 & 0 & 0 & 0.375 \\
\hline nws.seg.c & 0 & 0 & 0 & 0 & 0 & 0 & 0 & 0 & 0 & 0 & 0 & 0 & 0 & 0 & 1 & 0 & 0 & 0.333 \\
\hline pulse.A & 0 & 0 & 0 & 0 & 0 & 0 & 0 & 0 & 0 & 0 & 0 & 0 & 0 & 0 & 0 & 0 & 0 & 0.364 \\
\hline pulse.I & 0 & 0 & 0 & 0 & 0 & 0 & 0 & 0 & 0 & 0 & 0 & 0 & 0 & 0 & 1 & 0 & 0 & 0.213 \\
\hline pulse.I.a & 0 & 1 & 0 & 0 & 0 & 0 & 0 & 0 & 0 & 0 & 0 & 0 & 0 & 0 & 0 & 0 & 0 & 0.125 \\
\hline
\end{tabular}


TABLE V. (Continued)

\begin{tabular}{|c|c|c|c|c|c|c|c|c|c|c|c|c|c|c|c|c|c|c|}
\hline Call type & ahq & aws & aws.seg & click & c. 1 & c. 2 & c. 3 & c. 4 & c. 5 & c. 6 & dhq & dws & dws.seg & flatws & flatws.m & flatws. seg & $\mathrm{hq}$ & Call type error \\
\hline pulse.I.d & 0 & 0 & 0 & 0 & 0 & 0 & 0 & 0 & 0 & 0 & 0 & 1 & 0 & 0 & 0 & 0 & 0 & 0.200 \\
\hline rws & 0 & 17 & 0 & 0 & 0 & 0 & 0 & 0 & 0 & 0 & 0 & 0 & 0 & 0 & 2 & 0 & 0 & 0.463 \\
\hline rws.seg & 0 & 0 & 1 & 0 & 0 & 0 & 0 & 0 & 0 & 0 & 0 & 0 & 0 & 0 & 0 & 0 & 0 & 0.286 \\
\hline trill & 0 & 0 & 1 & 0 & 0 & 0 & 0 & 0 & 0 & 0 & 0 & 0 & 1 & 0 & 0 & 3 & 0 & 0.217 \\
\hline uws & 0 & 0 & 0 & 0 & 0 & 0 & 0 & 0 & 0 & 0 & 0 & 0 & 0 & 0 & 0 & 0 & 0 & 0.176 \\
\hline uws.seg & 0 & 0 & 0 & 0 & 0 & 0 & 0 & 0 & 0 & 0 & 0 & 0 & 0 & 0 & 0 & 0 & 0 & 1.000 \\
\hline Call type & modws & $\begin{array}{c}\text { modws. } \\
\text { m }\end{array}$ & $\begin{array}{l}\text { modws. } \\
\text { S }\end{array}$ & $\begin{array}{c}\text { modws. } \\
\text { seg }\end{array}$ & noisy & nws & $\begin{array}{l}\text { nws. } \\
\text { seg.b }\end{array}$ & $\begin{array}{l}\text { nws. } \\
\text { seg.c }\end{array}$ & $\begin{array}{c}\text { pulse. } \\
\text { A }\end{array}$ & $\begin{array}{c}\text { pulse. } \\
\text { I }\end{array}$ & $\begin{array}{c}\text { pulse. } \\
\text { I.a }\end{array}$ & $\begin{array}{l}\text { pulse. } \\
\text { I.d }\end{array}$ & rws & rws.seg & trill & uws & uws.seg & $\begin{array}{c}\text { Call } \\
\text { type error }\end{array}$ \\
\hline ahq & 0 & 0 & 0 & 0 & 0 & 0 & 0 & 0 & 0 & 0 & 0 & 0 & 0 & 0 & 0 & 0 & 0 & 0.000 \\
\hline aws & 0 & 0 & 0 & 0 & 0 & 0 & 0 & 0 & 0 & 0 & 0 & 0 & 12 & 0 & 0 & 0 & 0 & 0.186 \\
\hline aws.seg & 0 & 0 & 0 & 0 & 0 & 0 & 0 & 0 & 0 & 0 & 0 & 0 & 0 & 3 & 0 & 0 & 0 & 0.500 \\
\hline click & 0 & 0 & 0 & 0 & 0 & 0 & 0 & 0 & 0 & 1 & 0 & 0 & 0 & 0 & 1 & 0 & 0 & 1.000 \\
\hline c. 1 & 0 & 0 & 0 & 0 & 0 & 0 & 0 & 0 & 0 & 0 & 1 & 0 & 0 & 0 & 0 & 0 & 0 & 1.000 \\
\hline c. 2 & 0 & 0 & 0 & 0 & 0 & 0 & 0 & 0 & 0 & 0 & 0 & 0 & 0 & 0 & 0 & 0 & 0 & 1.000 \\
\hline c. 3 & 0 & 0 & 0 & 0 & 0 & 0 & 0 & 0 & 0 & 1 & 1 & 0 & 0 & 0 & 0 & 0 & 0 & 1.000 \\
\hline c. 4 & 0 & 0 & 0 & 0 & 0 & 0 & 0 & 0 & 0 & 0 & 0 & 0 & 0 & 0 & 0 & 0 & 0 & 0.000 \\
\hline c. 5 & 0 & 0 & 0 & 0 & 0 & 0 & 0 & 0 & 0 & 0 & 0 & 0 & 0 & 0 & 0 & 0 & 0 & 0.000 \\
\hline c. 6 & 0 & 0 & 0 & 0 & 0 & 0 & 0 & 0 & 0 & 0 & 0 & 0 & 0 & 0 & 0 & 0 & 0 & 0.000 \\
\hline dhq & 0 & 0 & 0 & 0 & 0 & 0 & 0 & 0 & 0 & 0 & 0 & 0 & 0 & 0 & 0 & 0 & 0 & 0.042 \\
\hline dws & 0 & 0 & 0 & 0 & 0 & 0 & 0 & 0 & 0 & 0 & 0 & 0 & 0 & 0 & 0 & 0 & 0 & 0.025 \\
\hline dws.seg & 0 & 0 & 0 & 0 & 0 & 0 & 0 & 0 & 0 & 0 & 0 & 0 & 0 & 0 & 0 & 0 & 0 & 0.037 \\
\hline flatws & 0 & 0 & 0 & 0 & 0 & 0 & 0 & 0 & 0 & 0 & 0 & 0 & 0 & 0 & 0 & 0 & 0 & 0.043 \\
\hline flatws.m & 0 & 0 & 0 & 0 & 0 & 0 & 0 & 0 & 0 & 0 & 0 & 0 & 1 & 0 & 0 & 1 & 0 & 0.077 \\
\hline flatws.seg & 0 & 0 & 0 & 0 & 0 & 0 & 0 & 0 & 0 & 0 & 0 & 0 & 0 & 0 & 2 & 0 & 0 & 0.200 \\
\hline hq & 0 & 0 & 0 & 0 & 0 & 0 & 0 & 0 & 0 & 0 & 0 & 0 & 0 & 0 & 0 & 1 & 0 & 0.041 \\
\hline modws & 17 & 8 & 3 & 0 & 0 & 0 & 0 & 0 & 0 & 0 & 0 & 0 & 0 & 0 & 0 & 0 & 0 & 0.414 \\
\hline modws.m & 8 & 25 & 2 & 0 & 0 & 0 & 0 & 0 & 0 & 0 & 0 & 0 & 0 & 0 & 0 & 0 & 0 & 0.286 \\
\hline modws.S & 0 & 0 & 58 & 0 & 0 & 0 & 0 & 0 & 0 & 0 & 0 & 0 & 0 & 0 & 0 & 0 & 0 & 0.017 \\
\hline modws.seg & 0 & 0 & 0 & 39 & 0 & 0 & 0 & 0 & 0 & 0 & 0 & 0 & 0 & 0 & 0 & 0 & 0 & 0.000 \\
\hline noisy & 0 & 0 & 0 & 0 & 0 & 0 & 0 & 0 & 1 & 1 & 0 & 0 & 0 & 0 & 0 & 0 & 0 & 1.000 \\
\hline nws & 0 & 0 & 0 & 0 & 0 & 23 & 0 & 0 & 0 & 0 & 0 & 0 & 0 & 0 & 0 & 18 & 0 & 0.489 \\
\hline nws.seg.b & 0 & 0 & 0 & 0 & 0 & 0 & 5 & 1 & 0 & 0 & 0 & 0 & 0 & 0 & 0 & 0 & 2 & 0.375 \\
\hline nws.seg.c & 0 & 0 & 0 & 0 & 0 & 1 & 1 & 8 & 0 & 0 & 0 & 0 & 0 & 0 & 0 & 0 & 1 & 0.333 \\
\hline pulse.A & 0 & 0 & 0 & 0 & 0 & 0 & 0 & 0 & 14 & 7 & 0 & 1 & 0 & 0 & 0 & 0 & 0 & 0.364 \\
\hline pulse.I & 0 & 0 & 0 & 1 & 0 & 0 & 1 & 0 & 5 & 37 & 0 & 2 & 0 & 0 & 0 & 0 & 0 & 0.213 \\
\hline pulse.I.a & 0 & 0 & 0 & 0 & 0 & 0 & 0 & 0 & 0 & 0 & 14 & 0 & 0 & 1 & 0 & 0 & 0 & 0.125 \\
\hline pulse.I.d & 0 & 0 & 0 & 0 & 0 & 0 & 0 & 0 & 1 & 4 & 0 & 24 & 0 & 0 & 0 & 0 & 0 & 0.200 \\
\hline rws & 0 & 0 & 0 & 0 & 0 & 0 & 0 & 0 & 0 & 0 & 0 & 0 & 22 & 0 & 0 & 0 & 0 & 0.463 \\
\hline rws.seg & 0 & 0 & 0 & 0 & 0 & 0 & 0 & 0 & 0 & 0 & 0 & 0 & 0 & 10 & 3 & 0 & 0 & 0.286 \\
\hline trill & 0 & 0 & 0 & 0 & 0 & 0 & 0 & 0 & 0 & 0 & 0 & 0 & 0 & 0 & 18 & 0 & 0 & 0.217 \\
\hline uws & 0 & 0 & 0 & 0 & 0 & 12 & 0 & 0 & 0 & 0 & 0 & 0 & 0 & 0 & 0 & 56 & 0 & 0.176 \\
\hline uws.seg & 0 & 0 & 0 & 0 & 0 & 0 & 3 & 3 & 0 & 0 & 0 & 0 & 0 & 0 & 0 & 0 & 0 & 1.000 \\
\hline
\end{tabular}

TABLE VI. Gini Index for the Random Forest analysis (Table V) of the eastern Beaufort Sea beluga call type classification.

\begin{tabular}{lc}
\hline \hline Variable & Mean decrease in Gini \\
\hline Trend & 139.29 \\
Inflection & 138.02 \\
Duration & 127.35 \\
BW & 118.90 \\
Steps & 82.08 \\
Range & 67.52 \\
PRR & 56.49 \\
Start & 50.89 \\
End & 47.39 \\
Maximum & 45.98 \\
Peak & 44.05 \\
Minimum & 41.55 \\
\hline \hline
\end{tabular}

${ }^{1}$ Reference to trade names does not imply endorsement by the National Marine Fisheries Service, NOAA.

Allen, B. M., and Angliss, R. P. (2013). "Alaska marine mammal stock assessments, 2012," in NOAA Technical Memorandum No. NMFSAFSC-245 (U.S. Department of Commerce, Washington, DC), pp. 1-291.

Angiel, N. M. (1997). "The vocal repertoire of the beluga whale in Bristol Bay, Alaska," Master's thesis, University of Washington, Seattle, WA.

Au, W. W. L., Carder, D. A., Penner, R. H., and Scronce, B. L. (1985).

"Demonstration of adaptation in beluga whale echolocation signals," J. Acoust. Soc. Am. 77, 726-730.

Bain, D. E. (1986). "Acoustic behavior of Orcinus: Sequences, periodicity, behavioral correlates and an automated technique for call classification," in Behavioral Biology of Killer Whales, edited by B. C. Kirkevold and J. S. Lockard (Liss, New York), pp. 335-371.

Belikov, R. A., and Bel'kovich, V. M. (2007). "Whistles of beluga whales in the reproductive gathering off Solovetskii Island in the White Sea," Acoust. Phys. 53, 528-534. 
Belikov, R. A., and Bel'kovich, V. M. (2008). "Communicative pulsed signals of beluga whales in the reproductive gathering off Solovetskii Island in the White Sea," Acoust. Phys. 54, 115-123.

Bel'kovich, V. M., and Shchekotov, M. N. (1990). Belukha. Povedenie i bioakustika v prirode (Beluga Whale: Behavior and Bioacoustics in Nature) (Inst. Okeanologii, Akad. Nauk SSSR, Moscow), pp. 1-183.

Bioacoustics Research Program (2011). "Raven Pro: Interactive Sound Analysis Software," version 1.4 (The Cornell Lab of Ornithology, Ithaca, NY).

Breiman, L. (2001). "Random forests," Machine Learn. 45, 5-32.

Breiman, L., Friedman, J. H., Olshen, R. A., and Stone, C. G. (1984). Classification and Regression Trees (Chapman and Hall, London, UK), pp. 1-359.

Busnel, R. H., and Dziedzic, A. (1966). "Acoustic signals of the pilot whale Globicephala melaena and of the porpoise Delphinus delphis and Phocoena phocoena," in Whales, Dolphins and Porpoises, edited by K. S. Norris (University of California Press, Berkeley, CA), pp. 608-648.

Chmelnitsky, E. G., and Ferguson, S. H. (2012). "Beluga whale, Delphinapterus leucas, vocalizations from the Churchill River, Manitoba, Canada," J. Acoust. Soc. Am. 131, 4821-4835.

Clark, C. W. (1982). "The acoustic repertoire of the southern right whale: A quantitative analysis," Anim. Behav. 30, 1060-1071.

Clarke, J. T., Christman, C. L., Brower, A. A., and Ferguson, M. C. (2012). "Distribution and relative abundance of marine mammals in the Alaskan Chukchi and Beaufort Seas, 2011," BOEM Annual Report No. OCSBOEM-2012-009, pp. 1-358.

Delarue, J., Laurinoll, M., and Martin, B. (2011). "Acoustic detections of beluga whales in the northeastern Chukchi Sea, July 2007 to July 2008," Arctic 64, 15-24.

Delarue, J., Todd, S. K., Van Parijs, S. M., and Di Iorio, L. (2009). "Geographic variation in northwest Atlantic fin whale (Balaenoptera physalus) song: Implications for stock structure assessment," J. Acoust. Soc. Am. 125, 1774-1782.

Dunlop, R. A., Noad, M. J., Cato, D. H., and Stokes, D. (2007). “The social vocalization repertoire of east Australian migrating humpback whales (Megaptera novaeangliae)," J. Acoust. Soc. Am. 122, 2893-2905.

Faucher, A. (1988). "The vocal repertoire of the St. Lawrence Estuary population of beluga whale (Delphinapterus leucas) and its behavioral, social and environmental contexts," Master's thesis, Dalhousie University, Halifax, Nova Scotia, Canada.

Ford, J. K. B. (1989). "Acoustic behaviour of resident killer whales (Orcinus orca) off Vancouver Island, British Columbia," Can. J. Zool. 67, 727-745.

Ford, J. K. B. (1991). "Vocal traditions among resident killer whales (Orcinus orca) in coastal waters of British Columbia," Can. J. Zool. 69, 1454-1483.

Garland, E. C., Berchok, C. L., and Castellote, M. (2015). "Temporal peaks in beluga whale (Delphinapterus leucas) acoustic detections in the northern Bering, northeastern Chukchi, and western Beaufort Seas: 2010-2011," Polar Biol. doi:10.1007/s00300-014-1636-1.

Garland, E. C., Lilley, M. S., Goldizen, A. W., Rekdahl, M. L., Garrigue, C., and Noad, M. J. (2012). "Improved versions of the Levenshtein distance method for comparing sequence information in animals' vocalisations: Tests using humpback whale song," Behaviour 149, 1413-1441.

Garland, E. C., Noad, M. J., Goldizen, A. W., Lilley, M. S., Rekdahl, M. L., Constantine, R., Garrigue, C., Daeschler Hauser, N., Poole, M. M., and Robbins, J. (2013). "Quantifying humpback whale song sequences to understand the dynamics of song exchange at the ocean basin scale," J. Acoust. Soc. Am. 133, 560-569.

Hauser, D. D. W., Laidre, K. L., Suydam, R. S., and Richard, P. R. (2014). "Population-specific home ranges and migration timing for Pacific Arctic beluga whales (Delphinapterus leucas)," Polar Biol. 37, 1171-1183.

Karlsen, J. D., Bisther, A., Lydersen, C., Haug, T., and Kovacs, K. M. (2002). "Summer vocalisations of adult male white whales (Delphinapterus leucas) in Svalbard, Norway," Polar Biol. 25, 808-817.
Kershenbaum, A., Ilany, A., Blaustein, L., and Geffen, E. (2012). "Syntactic structure and geographical dialects in the songs of male rock hyraxes," Proc. R. Soc. B 279, 2974-2981.

Liaw, A., and Wiener. M. (2002). "Classification and regression by randomForest," RNews $\mathbf{2 / 3}, 18-22$.

MacDougall-Shackleton, E. A., and MacDougall-Shackleton, S. A. (2001). "Cultural and genetic evolution in mountain white-crowned sparrows: Song dialects are associated with population structure," Evolution 55, 2568-2575.

Marler, P. (1970). "Vocalizations of East African monkeys: 1. Red colobus," Folia Primatol. 13, 81-91.

Miller, E. H. (1979). "An approach to the analysis of graded vocalizations of birds," Behav. Neural Biol. 27, 25-38.

Miller, P. J. O., and Bain, D. E. (2000). "Within-pod variation in killer whale calls," Anim. Behav. 60, 617-628.

Murray, S. O., Mercado, E., and Roitblat, H. L. (1998). "Characterizing the graded structure of false killer whale (Pseudorca crassidens) vocalizations," J. Acous. Soc. Am. 104, 1679-1688.

O'Corry-Crowe, G. M., Suydam, R. S., Rosenberg, A., Frost, K. J., and Dizon, A. E. (1997). "Phylogeography, population structure and dispersal patterns of the beluga whale Delphinapterus leucas in the western Nearctic revealed by mitochondrial DNA," Mol. Ecol. 6, 955-970.

Panova, E. M., Belikov, R. A., Agafonov, A. V., and Bel'kovich, V. M. (2012). "The relationship between the behavioral activity and the underwater vocalization of the beluga whale (Delphinapterus leucas)," Oceanology 52, 79-87, doi:10.1134/S000143701201016X.

Papale, E., Azzolin, M., Cascao, I., Gannier, A., Lammers, M. O., Martin, V. M., Oswald, J., Perez-Gil, M., Prieto, R., Silva, M. A., and Giacoma, C. (2014). "Macro- and micro-geographic variation of short-beaked common dolphin's whistles in the Mediterranean Sea and Atlantic Ocean," Ethol. Ecol. Evol. 26, 392-404.

$\mathrm{R}$ Foundation for Statistical Computing (2012). "R: A Language and Environment for Statistical Computing," R Foundation for Statistical Computing, Vienna, Austria.

Rankin, S., Archer, F., and Barlow, J. (2013). "Vocal activity of tropical dolphins is inhibited by the presence of killer whales, Orcinus orca," Mar. Mamm. Sci. 29, 679-690.

Rekdahl, M. L., Dunlop, R. A., Noad, M. J., and Goldizen, A. W. (2013). "Temporal stability and change in the social call repertoire of migrating humpback whales," J. Acoust. Soc. Am. 133, 1785-1795.

Seaman, G. A., Frost, K. J., and Lowry, L. F. (1985). "Investigations of belukha whales in coastal waters of western and northern Alaska. I. Distribution, abundance, and movements," NOAA OCS Final Report NA81-RAC-00049, pp. 1-60.

Sjare, B. L., and Smith, T. G. (1986). "The vocal repertoire of white whales, Delphinapterus leucas, summering in Cunningham Inlet, Northwest Territories," Can. J. Zool. 64, 407-415.

Suydam, R. S. (2009). "Age, growth, reproduction, and movements of beluga whales (Delphinapterus leucas) from the eastern Chukchi Sea," Ph.D. thesis, University of Washington, Seattle, WA.

Taruski, A. G. (1979). "The whistle repertoire of the north Atlantic pilot whale (Globicephala melaena) and its relationship to behavior and environment," in Behavior of Marine Animals. Cetaceans, edited by H. E. Winn and B. C. Olla (Plenum, New York), Vol. 3, pp. 345-368.

Watkins, W. A. (1967). "Harmonic interval: Fact or artifact in spectral analysis of pulse trains," in Marine Bioacoustics, edited by W. N. Tavolga (Pergamon, Oxford), pp. 15-42.

Whitehead, H., Dillon, M., Dufault, S., Weilgart, L., and Wright, J. (1998). "Non-geographically based population structure of South Pacific sperm whales: Dialects, fluke-markings and genetics," J. Anim. Ecol. 67, 253-262.

Wright, T. F., and Wilkinson, G. S. (2001). "Population genetic structure and vocal dialects in an Amazon parrot," Proc. R. Soc. B 268, 609-616. 